OPEN ACCESS

Edited by:

J. John Mann,

Columbia University, United States

Reviewed by:

Noam Schneck,

New York State Psychiatric Institute

(NYSPI), United States

Lydia Roos,

University of North Carolina at

Charlotte, United States

*Correspondence:

Annina Seiler

annina.seiler@usz.ch

Specialty section:

This article was submitted to

Psychosomatic Medicine,

a section of the journal

Frontiers in Psychiatry

Received: 24 May 2020

Accepted: 28 October 2020

Published: 03 December 2020

Citation:

Seiler A, von Känel $R$ and Slavich GM (2020) The Psychobiology of Bereavement and Health: A

Conceptual Review From the

Perspective of Social Signal Transduction Theory of Depression.

Front. Psychiatry 11:565239.

doi: 10.3389/fpsyt.2020.565239

\section{The Psychobiology of Bereavement and Health: A Conceptual Review From the Perspective of Social Signal Transduction Theory of Depression}

\author{
Annina Seiler ${ }^{1 *}$, Roland von Känel ${ }^{1}$ and George M. Slavich ${ }^{2}$ \\ ${ }^{1}$ Department of Consultation-Liaison Psychiatry and Psychosomatic Medicine, University Hospital Zurich and University of \\ Zurich, Zurich, Switzerland, ${ }^{2}$ Cousins Center for Psychoneuroimmunology and Department of Psychiatry and Biobehavioral \\ Sciences, University of California, Los Angeles, Los Angeles, CA, United States
}

Losing a spouse is considered one of the most stressful life events a person can experience. Particularly in the immediate weeks and months after the loss, bereavement is associated with a significantly increased risk of morbidity and mortality. Despite an abundance of research aimed at identifying risk factors for adverse health outcomes following marital death, the mechanisms through which mental and physical health problems emerge following bereavement remain poorly understood. To address this issue, the present review examines several pathways that may link bereavement and health, including inflammation and immune dysregulation, genetic and epigenetic changes, gut microbiota activity, and biological aging. We then describe how these processes may be viewed from the perspective of the Social Signal Transduction Theory of Depression to provide a novel framework for understanding individual differences in long-term trajectories of adjustment to interpersonal loss. Finally, we discuss several avenues for future research on psychobiological mechanisms linking bereavement with mental and physical health outcomes.

Keywords: bereavement, interpersonal loss, life stress, inflammation, immune system, biological aging, health, disease

\section{INTRODUCTION}

Losing a spouse can be a very stressful life event that places individuals at risk for mental and physical health problems $(1,2)$. Particularly in the immediate weeks and months following spousal loss, bereavement is associated with increased risk of multimorbidity and mortality (2-5), including an elevation in inflammation-related health problems (6-10), cardiovascular disease (CVD) $(8,11-14)$, and some types of cancer (12). Despite a large body of research in the trauma literature attempting to identify risk factors for adverse health outcomes following spousal bereavement, however, the mechanisms through which mental and physical health problems emerge following interpersonal loss remain poorly understood.

Over the past 30 years, the field of psychoneuroimmunology has helped elucidate how different life stressors affect autonomic nervous system, neuroendocrine, and immune processes that could in turn be relevant for understanding the psychobiology of bereavement $(15,16)$. In particular, the past decade has produced a substantial body of knowledge shedding light on how specific types of stressors can trigger increases in inflammation (15, 17-21), which has in turn been linked with the development of numerous disease conditions, including autoimmune disorders, CVD, and some 
cancers, as well as mortality (12). Consequently, bereavementrelated dysregulation in immune function may be one potential process that underlies the increased risk for morbidity and mortality seen in spousal bereaved individuals (22).

One strategy for better understanding the psychobiology of bereavement involves applying what we know about depression, which is also strongly precipitated by interpersonal loss. One model in particular, the Social Signal Transduction Theory of Depression (20), may be helpful for shedding light on how spousal loss and grief affect neural and immune processes that in turn structure risk for health problems following bereavement. In brief, this theory suggests that both early and later-life stress can promote neuro-inflammatory sensitivity to subsequently occurring stressors and thus heighten a person's vulnerability to physical and mental health problems across the lifespan. In the context of bereavement, this would occur if an individual with a history of past life stress exposure lost a terminally-ill spouse in adulthood after a sustained period of caregiving burden, in turn leading to mental and physical health problems that have an inflammatory basis.

Recently, Knowles et al. (23) published an excellent systematic review that focused on the link between bereavement and immune system functioning. The present review also examines links between bereavement and immune functioning but seeks to go beyond prior work by providing an integrated account of psychosocial, neural, immunologic, and genomic processes linking bereavement and health, as well as a description of how cumulative lifetime stress exposure may alter vulnerability to mental and physical health problems following spousal loss. To accomplish this goal, we conducted a PubMed literature search of all relevant studies published through October 2019 using the following key words: bereavement, mental health, physical health, psychobiology, stress, genetic, epigenetic, neuroendocrine, neuroimmune, inflammation, and immunity. To be considered for this review, articles had to be peer reviewed and written in English (see Supplementary Table 1). The psychometric instruments used in the eligible studies are summarized in Table 1.

\section{SOCIAL SIGNAL TRANSDUCTION THEORY OF DEPRESSION}

Stressful life events, especially those involving interpersonal loss, are known to activate several autonomic, neuroendocrine, and neuroimmune pathways that can lead to increased inflammatory activity (16), which, if sustained, can increase risk for inflammation-related physical and mental health problems $(20,24,25)$. Indeed, dysregulation of the immune system is a critical processes involved in the pathophysiology of various diseases, including infections, autoimmune diseases, CVD, and some cancers $(19,26,27)$. In addition, inflammatory activity can negatively affect mental health, and has been found to play a role in the development of anxiety disorders, post-traumatic stress disorder (PTSD), and depression (26). In this context, the cytokines interleukin (IL)-1 $\beta$ (IL-1 $\beta$ ), IL-6, and tumor necrosis factor- $\alpha$ (TNF- $\alpha)$ have been shown to be both upregulated
TABLE 1 | Assessment instruments used in the studies evaluated.

\begin{tabular}{|c|c|}
\hline Abbreviation & Full name \\
\hline ATQ-P & Automatic Thoughts Questionnaire-Positive version \\
\hline CSS & Crisis Support Scale \\
\hline CTQ & Childhood Trauma Questionnaire \\
\hline ECR-SF & Experiences in Close Relationships Questionnaire-Short Form \\
\hline GMRI & Grief and Meaning Reconstruction Inventory \\
\hline GMS & Grief Measurement Scale \\
\hline HAMD & Hamilton Anxiety and Depression Scale \\
\hline HRSD & Hamilton Rating Scale for Depression \\
\hline HTQ & Harvard Trauma Questionnaire-Part IV \\
\hline ICG & Inventory of Complicated Grief \\
\hline ICG-R & Inventory of Complicated Grief-Revised \\
\hline IES & Impact of Event Scale \\
\hline LOT & Life Orientation Test \\
\hline MCMI-III & Millon Clinical Multiaxial Inventory-III \\
\hline PSS & Perceived Stress Scale \\
\hline PERI-A & Psychiatric Epidemiology Research Interview-Anxiety Scale \\
\hline PERI-H & $\begin{array}{l}\text { Psychiatric Epidemiology Research } \\
\text { Interview-Helplessness-Hopelessness Scale }\end{array}$ \\
\hline PFQ-2 & Personal Feelings Questionnaire-2 \\
\hline PG-13 & Prolonged Grief 13 Items \\
\hline PSOM & Positive States of Mind \\
\hline PSQl & Pittsburgh Sleep Quality Index \\
\hline RPT & Relationship Profile Test \\
\hline SADS-L & $\begin{array}{l}\text { Lifetime Version of the Schedule for Affective Disorders and } \\
\text { Schizophrenia }\end{array}$ \\
\hline SCID-I & Structured Clinical Interview for DSM-IV Axis I Disorders \\
\hline SCL-90 & Symptom Checklist-90 \\
\hline SF-36 & 36-Item Short Form Health Survey \\
\hline SSI & Beck Scale for Suicidal Ideation \\
\hline STRAIN & Stress and Adversity Inventory \\
\hline TIPI & Ten-Item Personality Inventory \\
\hline TSC & Trauma Symptom Checklist \\
\hline TLEQ & Traumatic Life Events Questionnaire \\
\hline YES & Yale Evaluation of Suicidality scale \\
\hline
\end{tabular}

by interpersonal life stress and associated with poor health $(17,28-32)$.

One lingering question in this context has always been how exactly stressful experiences like interpersonal loss affect neurocognitive processes that in turn increase inflammation and inflammation-related disease risk. This important question is addressed by the Social Signal Transduction Theory of Depression $(20,33)$, which is a multilevel theory that describes neural, physiologic, molecular, and genomic pathways that link interpersonal stress exposure with internal biological processes that increase risk for depression and depression-related health problems. More specifically, this theory hypothesizes that cumulative lifetime stress exposure, which encompasses both acute negative life events (e.g., interpersonal loss) and chronic difficulties, can increase inflammatory activity through the activation of the autonomic nervous system 
(ANS), hypothalamic-pituitary-adrenal (HPA), and systemic inflammatory response. Although the temporary engagement of these systems is critical for survival during times of actual social or physical threat, sustained activation can occur that increase a person's vulnerability to physical and mental health problems that have an inflammatory component $(20,24,25,34,35)$.

Consistent with this theory, research has shown that genetic factors, epigenetic processes, personality traits (e.g., neuroticism), and social environmental conditions during childhood and adolescence (e.g., social/financial stress, uncertainty, abuse, or neglect) play a role in shaping individuals' sensitivity to lateroccurring adverse life events $(25,36)$. At the molecular level, epigenetic regulation of gene transcription can play an important role in helping individuals adapt to challenges posed by the external social environmental (37). However, stress-induced epigenetic changes can also lead to persistent increases in social stress-related physiological reactivity that last for months or years (38). In sum, therefore, social-environmental and genetic processes can independently and interactively affect the likelihood that a particular adverse life event will get converted into changes in gene expression that have the ability to influence health $(38,39)$.

A growing body of research is showing that the gut microbiota may also play an important role in shaping the activity of the enteric nervous system, ANS, neuroendocrine pathways, and immune system (40). This research has shown that the signaling pathways linking the central nervous system and gut are sensitive to social-environmental factors (41). Moreover, disruption of these systems can result in altered gastrointestinal function, HPAaxis activation, changes in immune responses, and, therefore, increased inflammation-related behavioral changes and disease susceptibility $(42,43)$.

In sum, the Social Signal Transduction Theory of Depression provides one illustration of how interpersonal loss can lead to specific changes in sympathetic nervous system (SNS) and HPA-axis activity that interact with genetic, personality, and social-environmental factors to promote immune dysregulation and increased inflammatory activity, especially in vulnerable individuals. These biological changes can in turn lead to depression-like behaviors, including anhedonia, helplessness, social withdrawal, and fatigue (26), which are characteristic of some bereaved individuals, thus making the Social Signal Transduction Theory of Depression a potentially useful framework for understanding psychosocial and biological aspects of bereavement (see Figure 1).

\section{PSYCHOBIOLOGY OF BEREAVEMENT FROM THE PERSPECTIVE OF SOCIAL SIGNAL TRANSDUCTION THEORY OF DEPRESSION}

For the purpose of this review, the term grief and bereavement have been conceptualized with slightly different meanings. Whereas, grief refers to a person's emotional response to a loss, bereavement refers to the time period when an individual experiences sadness, grief and mourning after a significant loss.
Typically, bereavement is the period during which time the most intensive grieving occurs (44).

The loss of a significant person in one's life is a unique social stressor that requires an individual to adapt, which differentiates it from other stressors such as caregiving, a conflictual marital relationship, or unemployment (45). To better understand psychological adjustment to significant interpersonal loss, research has employed concepts from the literatures on attachment theory, cognitive processing, and resilience. Early life attachment has been proposed to impact relationships in adulthood (46). In this regard, the loss of a spouse represents an attachment stressor that inherently has physiological effects, as attachment stress evolutionarily served to maintain proximity between bonded pairs (23).

As a highly stressful event, the death of a significant person is known to trigger biological responses via several autonomic, neuroendocrine, and inflammatory pathways (22). These responses, either directly or via interaction with the social environment, can cause alterations in biological functioning that include the onset of chronic low-grade inflammation, which can increase risk for sickness behaviors, infections, mental and physical health problems, and premature mortality in vulnerable individuals (26, 47-49). Consistent with this thinking, several lines of evidence indicate that stressful life events are strongly associated with altered immune function and the development of depression, especially for persons living in a high-risk environment (e.g., trauma exposure) who possess a genetic predisposition to depression (20,50-52). Moreover, clinical studies have shown that depressive symptoms are prevalent in widows and widowers during the first 2 years of bereavement, with a particular high risk for individuals with a history of depression $(53,54)$. To the extent that grief and depression are precipitated most strongly by the same types of major life stressors (i.e., sudden interpersonal loss), it may be possible to apply what we know about the psychobiology of depression (e.g., using the Social Signal Transduction Theory of Depression) to better understand the psychobiology of bereavement.

Importantly, the grief response depends on the nature and quality of the lost relationship (55). For example, the unintentional death of a spouse will be experienced differently than the death of a child, parent, or sibling, or the death of a close other by suicide (56). Furthermore, the unexpected death of a loved one may trigger different grief reactions than the loss of a spouse due to a terminal disease $(56,57)$. Hence, the psychobiology of bereavement may differ depending on the specific types of loss experienced (58). In the present article, therefore, we focus specifically on spousal bereavement as a particular type of life stressor.

In the following sections, we examine the applicability of the Social Signal Transduction Theory of Depression for studying psychobiological pathways that may link bereavement with multimorbidity and mortality. To do this, we review available research describing the impact of spousal loss on (a) mental and physical health, (b) inflammation and immune dysregulation, (c) genetic and epigenetic changes, (d) gut microbiota activity, and (e) biological aging. We also describe the effects of cumulative life stress exposure on health in bereaved individuals and explore 
psychobiological factors that have been linked to vulnerability and resilience to mental and physical health problems following significant interpersonal loss. Finally, we discuss how Social Signal Transduction Theory of Depression can be extended to bereavement and highlight several avenues of research that may be fruitful to pursue on this topic.

\section{The Impact of Bereavement on Mental Health}

As alluded to previously, the death of spouse is one of the most stressful life events a person can experience (59). Spousal bereavement due to cancer, for example, is usually preceded by a long illness trajectory, which is associated with high distress due to the spouse's progressive health deterioration, anticipatory grief about the spouse's inevitable death, adoption of supportive responsibilities, financial stressors, and disruption of the caregiver's social and personal life (60). Moreover, partners of patients who have been suffering from an advanced illness have been found to experience more emotional distress and adjustment problems, as well as greater pain, fatigue, sleep problems, and depression (61-65).

There is considerable variability in how people respond to the loss of a spouse. For example, although the vast majority of conjugally bereaved individuals are relatively resilient and adjust adequately without professional support $(66,67), 10-$ $20 \%$ of bereaved spouses develop intense, prolonged grief (6769). In addition, substantial evidence suggests that high levels of traumatic grief, depression, and anxiety at 6 months postloss predict the development of even more serious mental and physical health problems up to 25 months post-loss in spousal bereaved individuals, including suicidal ideation, cancer, and heart attacks (70).

Grief is a typical psychological and emotional reaction to losing a significant person that is characterized by symptoms of intense distress, anxiety, yearning, longing, and sadness, all of which usually subside over time (71). Although grieving symptoms are similar in some ways to symptoms of Major Depressive Disorder (MDD), as described by the Diagnostic and Statistical Manual of Mental Disorders (DSM-5), these two conditions are classified as distinct constructs $(72,73)$. Prolonged or persistent grief, by definition, is a debilitating condition following a significant loss that consists of persistent and pervasive longing for, or preoccupation with, the deceased person that persists for 6 months or longer. Moreover, it is characterized by its clinical features, including emotional pain (e.g., sadness, guilt, bitterness, anger), difficulty accepting the loss, emotional numbness, feeling that a part of one died, and difficulties in engaging in social or other activities (69). The diagnostic criteria for prolonged grief reactions are specified in the DSM-5 as Persistent Complex Bereavement Disorder (PCBD) (74) and in the International Statistical Classification of Diseases 11th Revision (ICD-11) as Prolonged Grief Disorder (PGD) $(75,76)$. PGD can be diagnosed at 6 months and PCBD at 12 months following the loss (77).

Bereavement is associated with short- and long-term health consequences. In one study that examined the early bereavement period (i.e., 6 months post-loss), prolonged grief was found in $12.3 \%$ of 56 bereaved adults between 20 and 50 years old who lost their spouse due to cancer (78). In another study of 132 adults, almost $30 \%$ of bereaved adults who lost a close relative to cancer met criteria for post-traumatic stress disorders 1 month postloss (79). Over the long term, complicated grief was found to be present in $24.6 \%$ of 668 cancer caregivers 9 months post-loss (80), and $48 \%$ of 88 cancer caregivers who suffered from increased levels of bereavement-related distress 3-5 years after the loss (81).

As briefly noted above, high levels of prolonged grief symptoms have been associated with greater disability and can compromise psychological and physical functioning for years, resulting in comorbid health problems. These health problems include impaired sleep $(82,83)$, depression $(9,84-86)$, suicidal ideation and attempts $(12,87)$, and anxiety and PTSD (88, 89 ), as well as adverse health behaviors (12), prolonged sick leave, and increased health services and medication use (90-92). Furthermore, grief severity assessed from 3 to 6 months postloss has been found to predict functional impairment, depressive symptoms, and impaired sleep up to 18 months following the loss $(86,93)$.

Of note, depression, and bereavement share considerable commonalities in terms of disease risk (e.g., CVD) and changes in immune function $(2,6,11,94-97)$. Some researchers have thus suggested that it is not interpersonal loss or bereavement but rather depression that is responsible for causing the increases in morbidity and mortality seen in bereaved individuals $(9,12$, $49,89,98)$. On the other hand, though, research has shown that grief and depression are independently associated with healthdamaging inflammation (99). Therefore, it may be the case that bereavement and depression are associated with similar but distinct patterns of inflammatory activity, and that interpersonal loss is a common precipitating stressful life event that may lead to both grief and depression.

\section{The Impact of Bereavement on Physical Health}

Bereavement has also been found to increase individuals' risk for physical health problems and, especially, immune-related illnesses such as CVD and cancer, in addition to increased mortality risk, within the first 3 years following a major loss $(12,92)$. Indeed, CVD is a major cause of morbidity and mortality following bereavement (100). In terms of underlying mechanisms, strong evidence has linked bereavement-related stress with increased risk for CVD via chronic low-grade inflammation, as commonly measured by circulating IL-6 or Creactive protein $(\mathrm{CRP})(27,101,102)$. In addition, elevated levels of CRP have been shown to be a strong prognostic factor for atherosclerosis and cardiovascular events $(103,104)$.

In terms of mortality risk, a meta-analysis of 15 prospective cohort studies and 2,263,888 participants found that relative to their married peers, recently bereaved spouses had a $41 \%$ increased risk of dying within the first 6 months following bereavement, independent of age and gender (overall RR 1.41; $95 \%$ CI 1.26, 1.57) (105). Another meta-analysis of more than 500 million people found a $23 \%$ increased risk of mortality among 


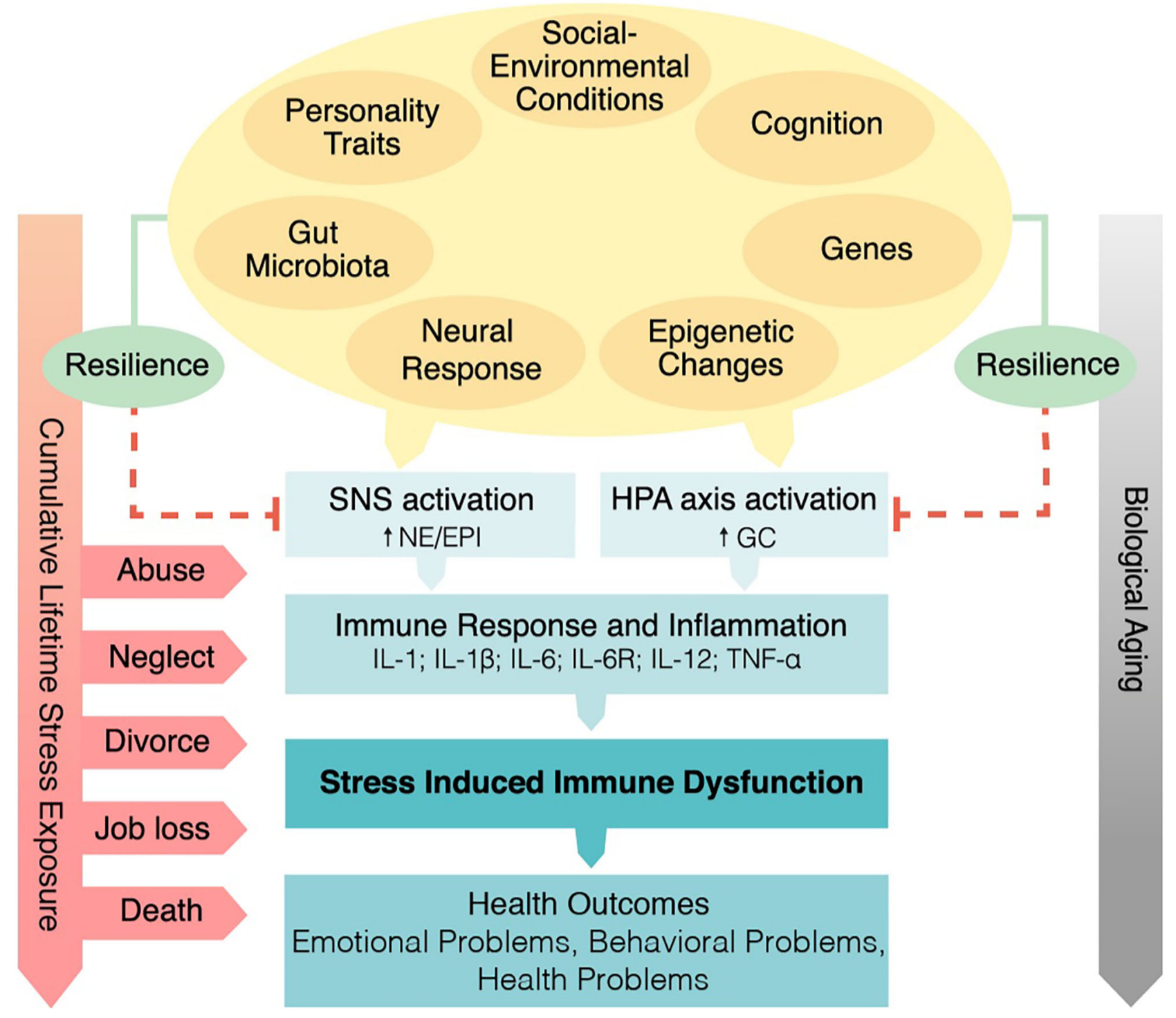

FIGURE 1 | Psychobiological mechanisms linking spousal bereavement and health from the perspective of the Social Signal Transduction Theory of Depression (20). The interplay between genetic factors, personality traits (e.g., neuroticism), and social-environmental conditions during childhood and adolescence (e.g., social/financial stress, uncertainty, abuse, or neglect) are hypothesized to play important roles in shaping individuals' neuro-inflammatory sensitivity to later-occurring life stressors, including interpersonal loss. Exposure to early life stress and subsequent stressors are hypothesized to heighten sympathetic nervous system and hypothalamic-pituitary-adrenal axis dysregulation, and to promote increased inflammatory activity in response to a significant loss. If chronic, elevated inflammatory activity can in turn lead to a variety of adverse emotional, behavioral, and health outcomes. SNS, sympathetic nervous system activation; NE, norepinephrine; EPI, epinephrine; HPA, hypothalamic-pituitary-adrenal; GC, glucocorticoid; IL-1, interleukin-1; IL-1 $\beta$, interleukin-1beta; IL-6, interleukin-6; IL-6R, interleukin-6 receptor; IL-12, interleukin-12; TNF- $\alpha$, tumor necrosis factor- $\alpha$.

widowers as compared to married individuals (HR 1.23; 95\% CI $1.19,1.28$ ), with a relatively higher risk for men (increased risk: 27\%) than women (increased risk: 15\%) (3). This phenomenon of increased mortality risk for bereaved individuals, specifically within the first 6 months after the interpersonal loss, has been called the "broken-heart phenomenon" (106) or "widowhood effect" (105). Nowadays, these terms have also been used in the context of Takotsubo cardiomyopathy, an acute reversible heart failure syndrome mimicking acute myocardial infarction that is frequently triggered by emotional stress, including loss and grief $(107,108)$.

Depression and stress are important risk factor for developing CVD, and depression has been associated with poorer coronary outcomes (94). Correspondingly, the death of a significant person is known as a key psychosocial risk factor for CVD (11). Research has shown that as compared to non-bereaved individuals, bereaved individuals exhibit lower heart rate variability and higher heart rate, systolic blood pressure, von Willebrand factor, 
factor VIII, and platelet/granulocyte counts (6, 8, 13, 109, 110). These findings have direct clinical relevance, given that prothrombotic changes have been associated with greater risk of CVD and mortality $(111,112)$. Of note, the adverse effects of stress on cardiovascular and other outcomes are often potentiated by unhealthy behaviors, including poor dietary choices and sleep hygiene, inadequate physical activity, alcohol and/or tobacco consumption, and poor medication adherence (113), all of which are risk factors for CVD in their own right.

Regarding the implications of bereavement for cancer risk, stress hormones, especially glucocorticoids, adrenaline, and noradrenaline, have multiple known effects on human tumor biology $(114,115)$. Specifically, SNS activation via adrenergic- and glucocorticoid-mediated mechanisms can increase inflammatory activity and alter immune defense mechanisms against tumors with implications for tumor progression (116). Consistent with these pathways, a few studies have suggested that bereavement is associated with increased risk for cancer incidence. For example, a historical study conducted by Prigerson et al. (12) found that bereaved individuals suffering from high levels of grief had a significantly greater risk of developing cancer within 6-25 months post-loss than those with low levels of grief, yet the type of cancer was not described. Additionally, the Pan American Health Organization/World Health Organization examined the effects of parental bereavement on cancer incidence and survival (117). This large cohort study included 6,284 Jewish Israelis who lost an adult son in the Yom Kippur War or in an accident between 1970 and 1977, and who were followed longitudinally for 20 years. There was an increased incidence of lymphatic and hematopoietic malignancies in both war-bereaved parents (OR 1.47) and parents of accident victims (OR 2.01). There also was an increased incidence of melanoma among both war-bereaved parents (OR 1.72) and parents of an accident victim (OR 4.62). Finally, in parents suffering from cancer before the loss, bereavement was associated with a relatively shorter survival time.

These data highlight a possible association between bereavement and cancer. Consistent with this work, data from the psycho-oncology literature suggest that the incidence of cancer recurrence may be higher during bereavement-related distress (114-116, 118-122). On the whole, though, the available evidence linking bereavement and cancer risk is not highly consistent and is certainly limited relative to the relatively large amount of research demonstrating an association between bereavement and CVD risk.

Another condition associated with bereavement is type 2 diabetes, a chronic metabolic disorder characterized by insulin resistance due to insufficient insulin secretion and action (123). A growing body of research indicates that stress plays a role in type 2 diabetes, both as a predictor of new-onset type 2 diabetes and as a prognostic factor for individuals with existing type 2 diabetes. Stress-related biological pathways that are believed to contribute to the pathogenesis of type 2 diabetes include chronic activation of the HPA axis, which can result in neuroendocrine dysfunction and dysregulated cortisol output (123) that leads to glucose intolerance and systemic insulin resistance (124).
Only a limited number of studies have investigated the onset of type 2 diabetes in the context of bereavement. One study reported a 1.4-fold increased risk of incident diabetes in parents who lost their child relative to age- and sex-matched non-bereaved parents (125). Another study found that bereavement-induced prenatal stress in mother increased the risk of insulin resistance by 1.3 -fold in their offspring; if grief was due to the death of an older sibling, the risk that the offspring developed type 2 diabetes during childhood or young adulthood was increased by 1.5-fold (126).

Taken together, these data provide relatively strong converging evidence that bereavement is associated with increased risk for poor mental and physical health. In most cases, the mechanisms underlying these bereavement-related health effects remain unclear. To address this issue, in the following sections we review psychoneuroimmunological pathways that may link bereavement with mental and physical health problems. We also discuss how these effects may be understood through the lens of the Social Signal Transduction Theory of Depression.

\section{PSYCHOBIOLOGICAL MECHANISMS LINKING BEREAVEMENT AND HEALTH}

\section{Bereavement-Induced Systemic Inflammation and Immune Dysregulation Neuroendocrine, Sympathetic, and Inflammatory Activation}

Several psychological, neural, and immunologic pathways may link bereavement with health. For example, it is well-known that stress activates the HPA axis and sympathetic-adrenal-medullary (SAM) axis, which in turn trigger the release of hormones that modulate immune function. Specific hormones involved in this stress-induced biological cascade include adrenocorticotropic hormone (ACTH), cortisol, growth hormone, prolactin, adrenaline, and noradrenaline (15). Through these mediators, life stress exposure can increase inflammatory activity and reduce anti-viral immune responses $(17,127)$.

In the context of bereavement, studies have begun to explore bereavement-related alterations in biomarkers of neuroendocrine and immune function. Results from these studies show that within the first 6 months following spousal loss, bereaved individuals exhibit evidence of reduced antibody response to vaccination (128), HPA-axis dysregulation [e.g., as indexed by higher cortisol levels and flatter diurnal cortisol slopes (9, 59, 129-132)], heightened systemic inflammation $(6,10,49,99,133)$, and impaired immune responses, as indexed by reduced functional activity of natural killer cells $(9,130)$.

Research has also suggested that these bereavement-related biological alterations, particularly those involving inflammation, may underlie the development of complicated grief. For example, in a recent study of 99 spousally bereaved individuals by Fagundes et al. (99), bereaved individuals with greater grief severity and higher levels of depression showed higher levels of the pro-inflammatory cytokines interferon gamma (INF- $\gamma$ ), IL-6, and TNF- $\alpha$ approximately 3 months after the death of their spouse as compared to those who had more 
mild emotional reactions to the loss. Sleep disturbances can also induce inflammation (134). In a study of 54 spousally bereaved and 47 non-bereaved individuals, self-reported sleep disturbance in bereaved individuals was not directly related to elevated inflammatory activity, but bereavement moderated the association between sleep disturbances and inflammation approximately three moths post-loss, after adjusting for depression (133). Therefore, sleep disturbance may be an important pathway linking bereavement with increased inflammation and subsequent health problems.

Mechanistically speaking, the pro-inflammatory cytokines IL$1 \beta$, IL- 6 , and TNF- $\alpha$ are believed to influence the activity of neurotransmitters that can in turn affect mood and induce depressive symptoms in vulnerable individuals $(28,135)$. Consistent with this understanding, some studies have argued that changes in immune function and related neurochemical processes during bereavement are the result of bereavementrelated depression as opposed to experiencing interpersonal loss or bereavement (136). Therefore, additional research is needed to examine the extent to which the increased inflammatory levels sometimes evident during or following bereavement are the result of an intense bereavement period itself vs. increases in depressive symptoms that sometime accompany bereavement.

\section{Immune Dysregulation}

Bereavement may also affect health by influencing immunity. Immunity is the natural or acquired resistance of an organism to bacterial or viral invaders, diseases, or infections, while having adequate tolerance to avoid allergy and autoimmune diseases (18). Lymphocytes, including $\mathrm{T}$ cells and $\mathrm{B}$ cells, as well as natural killer (NK) cells and macrophages, are the main types of cells of the immune system. T cells orchestrate the immune response via the production of cytokines and stimulate B cells to produce antibodies and signal killer cells to destroy antigen-displaying cells (137). Chronic stress, in turn, can induce low-grade inflammation and suppress immuno-protective cell function (18).

Studies investigating immune function in bereaved individuals have demonstrated $\mathrm{NK}$ cell activity suppression for up to 6 months following the sudden death of a relative $(9,130)$, lymphocyte proliferation for up to 2 months following spousal loss (138), and downregulated leukocyte gene expression in individuals who lost their spouse over the prior 2 years as compared to non-bereaved healthy adults (139). Seasonal influenza vaccination provides a useful paradigm to study individual differences in the inflammatory response. In one study that used this immunological challenge model in the context of bereavement, bereaved adults exhibited a reduced antibody titer response to influenza vaccination 1 year post-loss relative to non-bereaved adults (128). Together, these findings illustrate how bereavement can lead to long-lasting impairments in immunity that have implications for health.

\section{Bereavement-Induced Genetic and Epigenetic Changes}

Another pathway by which bereavement may influence health is by affecting genetic and epigenetic pathways. Early life stress exposure has been associated with heightened physiological stress sensitivity as indexed by inflammatory activity and reactivity, as well as with greater immune system dysregulation later in life $(30,47,140-143)$. In terms of gene expression, stress-induced epigenetic changes can result in altered gene expression (38).

The fields of psychoneuroimmunology, genetics, and genomics have only recently begun to examine genomic mechanisms that may underlie these effects. Although the literature examining bereavement-associated epigenetic changes remains scant, this research has already provided an interesting new window through which we may be able to better understand how bereavement affects health $(34,144)$. In this context, a few genetic polymorphisms have been investigated that could represent potential protective or risk factors in the face of adversity. For example, one recent cross-sectional study investigated the gene $\times$ environment $(G \times E)$ interaction effects of different genotypes and inflammation for 36 spousal bereaved older adults who experienced spousal loss over the past 23.75 months vs. 28 married individuals in order to elucidate factors predicting resilience during bereavement. The researchers found that spousally bereaved individuals exhibited higher levels of circulating inflammatory markers relative to non-bereaved individuals. Moreover, the authors identified a SNP in the IL-6-174 region that moderated individuals' vulnerability to increased systemic inflammation following the death of their spouse (49).

Relatedly, a cross-sectional study by O'Connor et al. (139) identified a genotype that helped explain the variability in grief severity experienced by older adults with and without complicated grief following the death of their partner or spouse. Individuals with both complicated grief $(N=12)$ and noncomplicated grief $(N=24)$ exhibited the upregulated expression of genes implicated in the activation of the immune response and downregulated expression of genes implicated in B lymphocyte responses. Moreover, individuals exhibiting complicated grief showed a substantial downregulated expression of Type I interferon transcripts.

It is possible that mutations in these genes may lead to the altered regulation of pro- and anti-inflammatory cytokine gene expression, in turn placing individuals experiencing bereavement-related distress at increased risk of experiencing immune-related health problems following bereavement (26). Furthermore, changes in gene expression following bereavement may interact with epigenetic changes that have occurred earlier in life (e.g., from early life stress exposure) to influence how an individual responds to the loss of a spouse in later adulthood. Likewise, bereavement itself may cause epigenetic changes that could increase a person's risk of subsequent health problems through the activation of the previously described inflammatory pathways (34).

Together, these data suggest that increased inflammatory activity may predominantly occur in genetically susceptible individuals who experience the loss of a significant person. This $\mathrm{G} \times \mathrm{E}$ effect may provide a possible mechanism through which bereavement-related stressors increase vulnerability for morbidity and mortality in bereaved individuals. The $\mathrm{G} \times \mathrm{E}$ effect 
may also help explain why some bereaved individuals develop mental and physical health problems following the death of a spouse while others do not.

\section{Bereavement-Induced Changes in the Gut Microbiota}

In addition, the gut microbiota may play a role in influencing health outcomes following bereavement. Evidence for this possibility comes from research documenting how acute and chronic stressors negatively impact the gut microbiome (41). Animal models provide experimental evidence for associations between early life stress exposure and low-grade inflammation, altered enteric microbiota, exaggerated stress reactivity, and visceral hypersensitivity $(42,145)$, emphasizing the impact of stress on microbial composition and activity. In humans, it is well-known that stress can cause nausea, vomiting, and abdominal pain (146). In addition, chronic life stressors such as financial problems, unemployment, and loss have been associated with an increased risk of developing functional gastrointestinal disorders, such as irritable bowel syndrome $(147,148)$. Moreover, accumulating evidence from clinical studies suggests a strong link between stress-induced disturbances along the gut microbiotaimmune-brain axis and chronic inflammatory disorders, such as allergies, autoimmunity, and inflammatory gastrointestinal disorders $(149,150)$, and mental health problems including anxiety disorders and depression (151-155).

In contrast with this general body of research on stress and the gut microbiota, only a few studies to date have investigated how stress may lead to changes in the gut microbiota in the context of bereavement. Moreover, much of the research examining the effects of stress on the gut microbiota is still from animal model studies (43). Therefore, the American Gastroenterology Association and American Psychosomatic Society have encouraged efforts to characterize pathways linking stress and the gut microbiota-immune-brain axis in large, prospective, longitudinal cohort studies to better understand microbiome composition and microbial function in healthy and diseased individuals (156). Ultimately, it is possible that stress may change microbiota and vice versa via neuroendocrine (157), inflammatory (158), and behavioral (e.g., depression) pathways (154), but additional research is needed on this topic in general and especially in the context of bereavement.

\section{Bereavement and Biological Aging}

Bereavement may also affect health through stress-induced accelerations in biological aging as indexed, for example, by telomere length. Telomeres are short DNA sequences that are located on the end of chromosomes. Telomeres protect chromosomes from degradation by forming a cap that provides chromosomal stability. Telomeres also regulate cellular replication and cellular lifespan (159). Of clinical importance, telomere length shortens with age (160), and extensive research has also shown that accelerated shortening of telomeres is associated with premature cell death, senescence, apoptosis, and carcinogenesis, in turn increasing morbidity and mortality (161). Furthermore, there is emerging evidence for an association of chronic stress with greater oxidative stress, lower telomerase activity, and shorter telomere length, indicating that stress may contribute to accelerated biological aging, thus providing a possible mechanism linking stress with health $(39,159,162,163)$.

Telomere attrition has emerged as a potentially useful biomarker of cellular aging that has shown associations with increased risk of various diseases and poorer survival (164). Additionally, the long-term effects of bereavement-related stress have been demonstrated in a study that investigated the impact of death or a sudden severe illness of a close family member during prenatal development. The study found that young adults with mothers who had experienced a death during prenatal development had shorter leukocyte telomere length as compared to young adults with mothers who had a pregnancy without experiencing death (165). These findings are of clinical importance for two reasons: first, telomere length in newborns and young adults has been related to maternal stress during pregnancy; and second, cellular aging can be influenced through prenatal stress, thereby potentially increasing an individual's susceptibility to infectious and autoimmune diseases in later life $(166,167)$.

Moreover, biological aging can affect the immune system by causing a progressive decline in functional immunity, referred to as immunosenescence, which diminishes humoral and cellular immune responses. Immunosenescence typically occurs in older individuals ( $\geq 65$ years old) $(168,169)$. Declining T-cell function is a well-characterized feature of immunosenescence, contributing to chronic low-grade inflammation (170). However, chronic stress also has been shown to suppress and dysregulate immune function via immunosenescence (162). Consequently, age-associated declines in immune function can contribute to many comorbid conditions and may render older individuals more vulnerable to further assaults on their immune system from things like stress, immune-related illnesses, and infectious diseases (171). For instance, systemic low-grade inflammation, as indexed by circulating levels of CRP and IL-6, has been identified as a significant risk factor for CVD in elderly individuals (102).

The loss of a spouse or partner occurs most frequently in later life and is thus a life event that is often experienced by individuals older than 65 years, mainly due to the loss of a spouse (172). Several studies have found evidence of reduced immunity in older adults who have experienced bereavement. For instance, older bereaved vs. non-bereaved individuals with a mean age of 75 years have been found to show a weaker antibody response to vaccination in the year after the loss of a spouse (128). Furthermore, older bereaved individuals $\left(M_{\text {age }}=72\right.$ years old) have been found to exhibit impaired neutrophil function, lower neutrophil reactive oxygen species (ROS) production, and a higher cortisol-to-dehydroepiandrosterone sulfate (DHEAS) ratio relative to younger adults $\left(M_{\text {age }}=32\right.$ years old) (173, 174). Of note, cortisol is generally immunosuppressive, whereas DHEAS (secreted by the adrenal gland) is immune-enhancing and counterbalances the effects of cortisol on the innate immune system (175). With aging, though, cortisol and DHEAS respond differently to stress, resulting in a negative regulatory effect on immune function (173).

In addition, from a molecular perspective, older bereaved adults (aged 61-83 years old) have been found to show the 
reduced expression of genes involved in the B lymphocyte immune response as compared to a sample of age- and sexmatched non-bereaved adults (139). The salient incidence of immune-related dysregulation in older bereaved individuals suggests a pivotal role of mutually enhancing effects of stress and inflammation on immunosenescence (176). Indeed, bereavement-related distress may promote a natural decline of the immune system and increase older adults' risk of bereavement-related morbidity and mortality (177).

\section{Cumulative Life Stress Exposure and Bereavement}

Chronic stress, especially when experienced in early life, can also affect health outcomes in bereaved individuals by setting the stage for long-lasting neurobiological changes that are associated with increased risk of later morbidity and mortality (178). Specifically, stress exposure during childhood can alter behavioral and physiological responses to acute and chronic stress in adulthood that in turn influence later-life risk for mental and physical health problems, including anxiety disorder, depression, CVD, and autoimmune and neurodegenerative disorders $(20,39,47,140$, 179). Epigenetic changes and immune system dysregulation may be potential pathways that underlie this link $(36,39,180)$. Indeed, the presence of multiple childhood adversities has been found to heighten emotional and physical reactivity to subsequent stress, which in turn activates genetic and epigenetic processes that may promote a proinflammatory phenotype (20).

In addition, cumulative life stress exposure is an important moderator of the association between acute life events, such as the loss of a spouse, and vulnerability to mental and physical health problems. As proposed by the Social Signal Transduction Theory of Depression, for example, greater lifetime stress exposure can increase neuro-inflammatory sensitization to adversity that increases a person's risk for immune-related mental and physical health problems in the face of subsequent interpersonal loss (20). Consistent with this formulation, among individuals with a history of childhood maltreatment, those who have experienced spousal loss have been found to be more likely to develop depressive symptoms than those who have not experienced such loss (84). These results suggest that adverse childhood experiences may set the stage for experiencing worse immunerelated health outcomes following a significant loss in adulthood.

\section{Psychosocial Factors Affecting Risk and Resilience in Bereavement}

Finally, several psychosocial factors can affect risk and resilience for poor health following bereavement. Resilience to stress is characterized by an individual's ability to maintain or restore relatively stable psychological and physical functioning when confronted with stressful life events, such as the death of a spouse (181). It has been hypothesized that resilience to such stressors arises from a combination of genetic factors (e.g., regulatory SNPs), personality traits (e.g., neuroticism, rejection sensitivity), and social-environmental conditions (e.g., life stress exposure, socioeconomic status) (182).
Bonanno et al. have conducted several seminal studies to better understand mechanisms underlying resilience (66, 181). For example, analyzing prospective longitudinal data from individuals enrolled prior to the death of a spouse, these investigators have identified four prototypical grieving trajectories: resilience $(66.3 \%)$ and chronic depression (14.5\%), followed by depressed improved (10.1\%), and chronic grief $(9.1 \%)(183,184)$. Contrary to expectations, for most individuals ( $\sim 60 \%)$, grief subsided over the initial weeks and months following the loss, indicating that most people are relatively resilient to interpersonal loss (184). However, even among resilient individuals, a majority showed grief reactions as characterized by transient distress, emotional pain, yearning, intrusive cognition, and rumination (185). In turn, only a small subgroup of grieving individuals exhibited severe grief that persisted for years after the marital loss $(183,184)$.

Psychosocial factors that appear to help buffer the negative effects associated with interpersonal loss include social support (186-188), secure attachment style $(46,189)$, positive emotions $(129,188,190)$, optimism (191), cognitive flexibility (including positive reappraisal and acceptance) (192), and spirituality, including religiosity (193). In contrast, there are numerous psychosocial factors that have been found to weaken resilience to loss and grief, contributing to grief severity and prolonged grief reactions. These risk factors include the characteristics of spousal death [e.g., context of spousal illness, caregiving strain, lack of preparation for the death, traumatic loss $(67,194)]$, relationship quality [e.g., close kinship relationship, affection, intimacy, care, understanding, conflicts, ambivalence, and dependency in relationship $(67,195)]$, intrapersonal factors [e.g., extraversion, neuroticism, insecure, anxious or avoidant attachment styles, poor emotion regulation, negative cognition, pre-loss depression $(67,196,197)]$, and interpersonal factors [e.g., low social and emotional support, financial hardships (67)].

In the bereavement literature, most studies that have been conducted so far have investigated group differences or correlates of bereavement, and only a few have examined biomarkers of resilience and vulnerability for bereavement-related morbidity. In this context, Buckley et al. (6) examined predictors of increased risk for thrombotic changes that might contribute to cardiovascular risk in the initial weeks following the death of a spouse and found a potential role for neutrophils, von Willebrand factor antigen, Factor VIII, and platelet/monocyte/granulocytes. Smoking was associated with a higher neutrophil count in acutely bereaved individuals and accounted for $6 \%$ of the shared variance $\left(r^{2}=0.06, p=0.02\right)$. Moreover, duration of relationship between spousal bereaved and deceased spouse $(p=0.03)$ and smoking $(p=0.001)$ were found to be associated with higher platelet/granulocyte aggregate levels, accounting collectively for $14 \%$ of shared variance $\left(r^{2}=0.14\right)$.

In addition to this research, two studies have examined changes in immune function following spousal loss while differentiating between grief severity and depression. The first study by Fagundes et al. (99) found that grief severity and depression were independently associated with increased systemic inflammation (e.g., IL-6, TNF- $\alpha$, IFN-y) in bereaved individuals approximately 3 months following the loss of a 
spouse. Furthermore, in the same study, MDD was a significant predictor of participants' levels of the proinflammatory cytokines IL-6, TNF- $\alpha$, INF- $\gamma$, and IL-17A following spousal loss. Contrary to expectation, depression did not moderate the association between grief severity and inflammation. Likewise, a second study identified fatigue (as indexed by the SF-36 Energy/Fatigue sub-score) as a predictor of low-grade inflammation (as measured by CRP) in bereaved individuals 1 month following the loss of a spouse (10).

In general, these findings documenting psychosocial factors associated with risk and resilience in bereavement are preliminary and require replication to determine their reliability and relevance for predicting vulnerability to bereavement-related morbidity. Furthermore, most of the studies in this area have used cross-sectional, post-interpersonal loss research designs. Studies that include pre-loss measures of neuroendocrine and immune biomarkers, and that follow participants over time, are therefore needed.

\section{DISCUSSION}

\section{Bereavement From the Perspective of the Social Signal Transduction Theory of Depression}

As discussed at the beginning of this review, we believe that psychobiological processes linking bereavement and health can be viewed from the perspective of the Social Signal Transduction Theory of Depression in order to provide one possible framework for better understanding processes that may underlie individual difference in risk and resilience to interpersonal loss. More specifically, the Social Signal Transduction Theory of Depression describes neural, physiologic, molecular, and genomic mechanisms linking interpersonal loss and health, as well as several moderators that can influence the effects of life stress on immune function and health, such as age, sex, and early life, adulthood, and cumulative lifetime stress exposure. Another important feature of the theory is that it differentiates between different types of life stressors and also accounts for individual characteristics-including both personality and genetic traitsthat may render an individual differentially susceptible to the negative effects of stress and bereavement. Insights from this theory may thus help to address several existing questions in the bereavement literature, including why some individuals are more resilient than others to interpersonal loss, why cumulative life stress exposure is a strong predictor of morbidity and mortality in bereaved individuals, and why bereavement is associated with an increased risk of experiencing physical health problems. In light of this, we believe that identifying how social and biological factors identified by this theory might help explain differences in bereavement severity and persistence is an important topic for future research.

Integrating the consequences of the loss of a significant individual into the Social Signal Transduction Theory of Depression seems to be feasible with some modifications. For example, the Social Signal Transduction Theory of Depression emphasize that stressors experienced over time and exert a cumulative effect on neural and immunologic functioning that sensitizes a person to future stressors, such as interpersonal loss. In this model, the death of a loved one is regarded as a unique, complex stressor that can involve several types of adversity, including housing difficulties, financial strain, physical relocation, retirement, and the loss of daily routines and meaning in life $(198,199)$.

Relative to other topics in psychoneuroimmunology, the grief, loss, and bereavement literature has generated very few data documenting how lifetime stress exposure affects psychological, neural, and immunologic outcomes in bereaved individuals over time. It is possible that the severity or taboo of discussing grief has rendered the investigation of mental and physical health problems following spousal bereavement difficult. Moreover, obtaining funding for studies designed to examine health outcomes among bereaved individuals (as opposed to patients) can be difficult. As a result of these factors, despite the great importance of this topic, the health consequences of bereavement remain poorly understood $(200,201)$.

\section{FUTURE DIRECTIONS}

To better understand how bereavement affects health, we believe there is a pressing need to study how bereavement leads to changes in psychological, neural, and immunologic functioning. Biobehavioral responses to grief, epigenetic changes, cumulative life stress exposure, and neural sensitivity to stress could each represent potential mechanisms linking bereavement and health. Therefore, it will be important to adopt a multidimensional approach to studying bereavement that involves assessing how these and other processes interact and change over time to structure differences in disease risk and longevity in the context of bereavement. Below, we discuss several direction for future research along these lines.

First, the early identification of individuals who are at the greatest risk of experiencing poor health outcomes following the death of a significant person is an important aim of precision medicine and disease prevention initiatives (202). Encouraging bereaved individuals to provide mental health and biological data will help advance research on how bereavement impacts mental and physical health. This knowledge can in turn help prevent or treat mental and physical health problems in bereaved individuals, especially those deemed to be at high risk as a function of their psychosocial or biological status. Ultimately, identifying biobehavioral mechanisms that can be modified or targeted early on in the bereavement process is an important and clinically relevant step toward the development of treatments that improve health outcomes in bereaved spouses.

Second, additional research is warranted to better understand the clinical significance, timing, duration, and trajectories of immune changes that occur following interpersonal loss (22). Large-scale longitudinal studies that systematically collect data on mental and physical health outcomes prior to and after spousal bereavement are needed. This longitudinal approach will help identify profiles that predict poor responses to the death of a significant person and thus aid in the identification of people who 
would benefit from personalized interventions and, moreover, the initial design of such interventions.

Third, studies investigating the biological bases of stress resilience will be important for elucidating processes that may help promote psychosocial resilience to interpersonal loss (203). From the perspective of the Social Signal Transduction Theory of Depression, vulnerability and resilience arises from a combination of social-environmental conditions (e.g., abuse or neglect, interpersonal, or financial difficulties), neurocognitive processes (e.g., perceptions of threat), social factors (e.g., social support), and genetics mechanisms (e.g., regulatory SNPs). According to this perspective, pre-loss neurocognitive, immunologic, and genetic functioning are important factors that help shape how a person is likely to respond to a significant interpersonal loss. Therefore, future studies examining psychobiological factors of resilience in bereavement could benefit from investigating $G \times E$ interaction effects by systematically assessing cumulative lifetime stress exposure (204) in addition to other predisposing psychosocial and biological factors that may confer increased vulnerability to the death of a significant person (38).

Fourth, it will be important to study health behaviors, such as smoking, diet, sleep, and exercise, which are not presently accounted for in the Social Signal Transduction Theory of Depression and that are rarely discussed in psychobiological models of bereavement. Some research has shown that bereavement is associated with negative health behaviors, especially diet and sleep $(205,206)$, but this literature is small for a topic that deserves serious attention.

Finally, investigating the interplay between multiple psychological and biological markers of stress over time involves substantial analytic computational complexity. Therefore, we believe that multilevel statistical approaches such as structural equation modeling and latent growth mixture modeling will be helpful for characterizing inter-individual differences in intra-individual changes over time (207).

\section{CONCLUSION}

In conclusion, the death of a spouse is considered one of the most stressful life events a person can experience. In addition

\section{REFERENCES}

1. Holmes TH, Rahe RH. The social readjustment rating scale. J Psychosom Res. (1967) 11:213-8. doi: 10.1016/0022-3999(67)90010-4

2. Stahl ST, Arnold AM, Chen JY, Anderson S, Schulz R. Mortality after bereavement: the role of cardiovascular disease and depression. Psychosom Med. (2016) 78:697-703. doi: 10.1097/PSY.00000000000 00317

3. Shor E, Roelfs DJ, Curreli M, Clemow L, Burg MM, Schwartz JE. Widowhood and mortality: a meta-analysis and meta-regression. Demography. (2012) 49:575-606. doi: 10.1007/s13524-012-0096-x

4. Hart CL, Hole DJ, Lawlor DA, Smith GD, Lever TF. Effect of conjugal bereavement on mortality of the bereaved spouse in participants of the renfrew/paisley study. J Epidemiol Commun Health. (2007) 61:455-60. doi: 10.1136/jech.2006.052043 to increasing risk for depression, spousal death can lead to increased risk for a variety of somatic and physical diseases, as well as early mortality. Our goal with the present review was to help make sense out of these effects by reviewing social, psychological, immunologic, and genetic processes that have the potential to shape vulnerability to morbidity and mortality following spousal bereavement. We also related these processes to the Social Signal Transduction Theory of Depression, which we believe is one useful, multi-level framework that can be used to understand how social stressors affect psychobiological processes that impact health. In terms of future studies, it will be important to explore the associations described herein to help identify individuals at high risk for poor health outcomes following the death of a significant person. This knowledge could help to elucidate biobehavioral mechanisms that clinicians could in turn target early after a loss to improve health outcomes in bereaved spouses. Given the centrality of interpersonal loss to the human experience, we believe that much more research is needed to understand how exactly spousal bereavement affects health and how we can translate this knowledge to increase psychosocial resilience to such stress.

\section{AUTHOR CONTRIBUTIONS}

All authors developed the concept for this article. The initial draft was written by AS and subsequently edited by RK and GS. All authors read and approved the final version for publication.

\section{FUNDING}

GS was supported in part by a Society in Science-Branco Weiss Fellowship, NARSAD Young Investigator Grant \#23958 from the Brain \& Behavior Research Foundation, and National Institutes of Health grant K08 MH103443.

\section{SUPPLEMENTARY MATERIAL}

The Supplementary Material for this article can be found online at: https:/www.frontiersin.org/articles/10.3389/fpsyt. 2020.565239/full\#supplementary-material

5. Espinosa J, Evans WN. Heightened mortality after the death of a spouse: marriage protection or marriage selection? J Health Econ. (2008) 27:1326-42. doi: 10.1016/j.jhealeco.2008.04.001

6. Buckley T, Morel-Kopp MC, Ward C, Bartrop R, McKinley S, Mihailidou $\mathrm{AS}$, et al. Inflammatory and thrombotic changes in early bereavement: a prospective evaluation. Eur J Prev Cardiol. (2012) 19:1145-52. doi: $10.1177 / 1741826711421686$

7. Cohen M, Granger S, Fuller-Thomson E. The association between bereavement and biomarkers of inflammation. Behav Med. (2015) 41:49-59. doi: 10.1080/08964289.2013.866539

8. Fagundes CP, Murdock KW, LeRoy A, Baameur F, Thayer JF, Heijnen C. Spousal bereavement is associated with more pronounced ex vivo cytokine production and lower heart rate variability: mechanisms underlying cardiovascular risk? Psychoneuroendocrinology. (2018) 93:65-71. doi: 10.1016/j.psyneuen.2018.04.010 
9. Gerra G, Monti D, Panerai AE, Sacerdote P, Anderlini R, Avanzini P, et al. Long-term immune-endocrine effects of bereavement: relationships with anxiety levels and mood. Psychiatry Res. (2003) 121:145-58. doi: 10.1016/S0165-1781(03)00255-5

10. Seiler A, Murdock KW, Fagundes CP. Impaired mental health and lowgrade inflammation among fatigued bereaved individuals. J Psychosom Res. 112:40-6. doi: 10.1016/j.jpsychores.2018.06.010

11. Carey IM, Shah SM, DeWilde S, Harris T, Victor CR, Cook DG. Increased risk of acute cardiovascular events after partner bereavement: a matched cohort study. JAMA Intern Med. (2014) 174:598-605. doi: 10.1001/jamainternmed.2013.14558

12. Prigerson HG, Bierhals AJ, Kasl SV, Reynolds CF, 3rd, Shear MK, Day N, et al. Traumatic grief as a risk factor for mental and physical morbidity. Am J Psychiatry. (1997) 154:616-23. doi: 10.1176/ajp.154.5.616

13. Buckley T, Stannard A, Bartrop R, McKinley S, Ward C, Mihailidou AS, et al. Effect of early bereavement on heart rate and heart rate variability. Am J Cardiol. (2012) 110:1378-83. doi: 10.1016/j.amjcard.2012.06.045

14. Aalbaek FS, Graff S, Vestergaard M. Risk of stroke after bereavementa systematic literature review. Acta Neurol Scand. (2017) 136:293-7. doi: $10.1111 /$ ane. 12736

15. Glaser R, Kiecolt-Glaser JK. Stress-induced immune dysfunction: implications for health. Nat Rev Immunol. (2005) 5:243-51. doi: 10.1038/nri1571

16. Hansel A, Hong S, Camara RJ, von Kanel R. Inflammation as a psychophysiological biomarker in chronic psychosocial stress. Neurosci Biobehav Rev. (2010) 35:115-21. doi: 10.1016/j.neubiorev.2009.12.012

17. Cohen S, Janicki-Deverts D, Doyle WJ, Miller GE, Frank E, Rabin BS, et al. Chronic stress, glucocorticoid receptor resistance, inflammation, and disease risk. Proc Natl Acad Sci USA. (2012) 109:5995-9. doi: $10.1073 /$ pnas. 1118355109

18. Dhabhar FS. Effects of stress on immune function: the good, the bad, and the beautiful. Immunol Res. (2014) 58:193-210. doi: 10.1007/s12026-0148517-0

19. Seiler A, Fagundes CP, Christian LM. The impact of everyday stressors on the immune system and health. In: Choukèr A. editor. Stress Challenges and Immunity in Space. From Mechanisms to Monitoring and Preventive Strategies, 2nd Edn. Berlin; Heidelberg: Springer International Publishing (2020). p. 71-91.

20. Slavich GM, Irwin MR. From stress to inflammation and major depressive disorder: a social signal transduction theory of depression. Psychol Bull. (2014) 140:774-815. doi: 10.1037/a0035302

21. Furman D, Campisi J, Verdin E, Carrera-Bastos P, Targ S, Franceschi C, et al. Chronic inflammation in the etiology of disease across the life span. Nat Med. (2019) 25:1822-32. doi: 10.1038/s41591-019-0675-0

22. O'Connor MF. Grief: a brief history of research on how body, mind, and brain adapt. Psychosom Med. (2019) 81:731-8. doi: 10.1097/PSY.0000000000000717

23. Knowles LM, Ruiz JM, O'Connor MF. A systematic review of the association between bereavement and biomarkers of immune function. Psychosom Med. (2019) 81:415-33. doi: 10.1097/PSY.0000000000000693

24. Hostinar CE, Nusslock R, Miller GE. Future directions in the study of early-life stress and physical and emotional health: implications of the neuroimmune network hypothesis. J Clin Child Adolesc Psychol. (2018) 47:142-56. doi: 10.1080/15374416.2016.1266647

25. Muscatell KA, Dedovic K, Slavich GM, Jarcho MR, Breen EC, Bower JE, et al. Neural mechanisms linking social status and inflammatory responses to social stress. Soc Cogn Affect Neurosci. (2016) 11:915-22. doi: 10.1093/scan/nsw025

26. Dantzer R, O'Connor JC, Freund GG, Johnson RW, Kelley KW. From inflammation to sickness and depression: when the immune system subjugates the brain. Nat Rev Neurosci. (2008) 9:46-56. doi: 10.1038/nrn2297

27. Wirtz PH, von Kanel R. Psychological stress, inflammation, and coronary heart disease. Curr Cardiol Rep. (2017) 19:111. doi: 10.1007/s11886-017-0919-x

28. Hodes GE, Ménard C, Russo SJ. integrating interleukin-6 into depression diagnosis and treatment. Neurobiol Stress. (2016) 4:15-22. doi: 10.1016/j.ynstr.2016.03.003

29. Rohleder N, Aringer M, Boentert $M$. Role of interleukin-6 in stress, sleep, and fatigue. Ann N Y Acad Sci. (2012) 1261:88-96. doi: 10.1111/j.1749-6632.2012.06634.x
30. Ajdacic-Gross V, Mutsch M, Rodgers S, Tesic A, Muller M, Seifritz E, et al. A step beyond the hygiene hypothesis-immune-mediated classes determined in a population-based study. BMC Med. (2019) 17:75. doi: 10.1186/s12916-019-1311-z

31. Irwin MR, Olmstead R, Carroll JE. Sleep disturbance, sleep duration, and inflammation: a systematic review and meta-analysis of cohort studies and experimental sleep deprivation. Biol Psychiatry. (2016) 80:40-52. doi: 10.1016/j.biopsych.2015.05.014

32. Raposa EB, Bower JE, Hammen CL, Najman JM, Brennan PA. A developmental pathway from early life stress to inflammation: the role of negative health behaviors. Psychol Sci. (2014) 25:1268-74. doi: 10.1177/0956797614530570

33. Slavich GM, Sacher J. Stress, sex hormones, inflammation, and major depressive disorder: extending social signal transduction theory of depression to account for sex differences in mood disorders. Psychopharmacology. (2019) 236:3063-79. doi: 10.1007/s00213-019-05326-9

34. Slavich GM, Cole SW. The emerging field of human social genomics. Clin Psychol Sci. (2013) 1:331-48. doi: 10.1177/2167702613478594

35. Kiecolt-Glaser JK, Wilson SJ, Madison A. Marriage and gut (microbiome) feelings: tracing novel dyadic pathways to accelerated aging. Psychosom Med. (2018) 81:704-10. doi: 10.1097/PSY.0000000000000647

36. Murdock KW, Seiler A, Chirinos DA, Garcini LM, Acebo SL, Cohen $\mathrm{S}$, et al. Low childhood subjective social status and telomere length in adulthood: the role of attachment orientations. Dev Psychobiol. (2018) 60:340-6. doi: 10.1002/dev.21601

37. Feinberg AP. Phenotypic plasticity and the epigenetics of human disease. Nature. (2007) 447:433-40. doi: 10.1038/nature05919

38. Assareh AA, Sharpley CF, McFarlane JR, Sachdev PS. Biological determinants of depression following bereavement. Neurosci Biobehav Rev. (2015) 49:17181. doi: 10.1016/j.neubiorev.2014.12.013

39. Mayer SE, Prather AA, Puterman E, Lin J, Arenander J, Coccia $\mathrm{M}$, et al. Cumulative lifetime stress exposure and leukocyte telomere length attrition: the unique role of stressor duration and exposure timing. Psychoneuroendocrinology. (2019) 104:210-8. doi: 10.1016/j.psyneuen.2019.03.002

40. Foster JA, Rinaman L, Cryan JF. Stress \& the gut-brain axis: regulation by the microbiome. Neurobiol Stress. (2017) 7:124-36. doi: 10.1016/j.ynstr.2017.03.001

41. Moloney RD, Desbonnet L, Clarke G, Dinan TG, Cryan JF. The microbiome: stress, health and disease. Mamm Genome. (2014) 25:49-74. doi: 10.1007/s00335-013-9488-5

42. O'Mahony SM, Hyland NP, Dinan TG, Cryan JF. Maternal separation as a model of brain-gut axis dysfunction. Psychopharmacology. (2011) 214:71-88. doi: 10.1007/s00213-010-2010-9

43. Tetel MJ, de Vries GJ, Melcangi RC, Panzica G, O’Mahony SM. Steroids, stress and the gut microbiome-brain axis. J Neuroendocrinol. (2018) 30:12548. doi: 10.1111/jne. 12548

44. Grief Reaction. StatPearls Publishing. (2020) Available online at: https://www. ncbi.nlm.nih.gov/books/NBK507832/ (accessed March 10, 2020).

45. Kiecolt-Glaser JK, Gouin JP, Hantsoo L. Close relationships, inflammation, and health. Neurosci Biobehav Rev. (2010) 35:33-8. doi: 10.1016/j.neubiorev.2009.09.003

46. Bowlby EJM. Attachment and Loss: Sadness and Depression. New York, NY: Basic Books (1980).

47. Miller GE, Chen E, Parker KJ. Psychological stress in childhood and susceptibility to the chronic diseases of aging: moving toward a model of behavioral and biological mechanisms. Psychol Bull. (2011) 137:959-97. doi: $10.1037 / \mathrm{a} 0024768$

48. Miller GE, Cole SW. Clustering of depression and inflammation in adolescents previously exposed to childhood adversity. Biol Psychiatry. (2012) 72:34-40. doi: 10.1016/j.biopsych.2012.02.034

49. Schultze-Florey CR, Martinez-Maza O, Magpantay L, Breen EC, Irwin MR, Gundel H, et al. When grief makes you sick: bereavement induced systemic inflammation is a question of genotype. Brain Behav Immun. (2012) 26:106671. doi: 10.1016/j.bbi.2012.06.009

50. Kendler KS, Karkowski LM, Prescott CA. Causal relationship between stressful life events and the onset of major depression. Am J Psychiatry. (1999) 156:837-41. doi: 10.1176/ajp.156.6.837

51. Kuhlman KR, Robles TF, Haydon MD, Dooley L, Boyle CC, Bower JE. Early life stress sensitizes individuals to the psychological correlates 
of mild fluctuations in inflammation. Dev Psychobiol. (2019) 62:400-8. doi: 10.1002/dev.21908

52. Dekel S, Ein-Dor T, Rosen JB, Bonanno GA. Differences in cortisol response to trauma activation in individuals with and without comorbid PTSD and depression. Front Psychol. (2017) 8:797. doi: 10.3389/fpsyg.2017.00797

53. Zisook S, Shuchter SR. Depression through the first year after the death of a spouse. Am J Psychiatry. (1991) 148:1346-52. doi: 10.1176/ajp.148.10.1346

54. Zisook S, Shuchter SR, Sledge PA, Paulus M, Judd LL. The spectrum of depressive phenomena after spousal bereavement. J Clin Psychiatry. (1994) 55:29-36

55. Weiss RS. Grief, bonds and relationships. In: Stroebe M, Hansson RO, Strobe W, Schut H, editor. Handbook of Bereavement Research: Consequences, Coping, and Care. Washington, DC: American Psychological Association (2001) p. 47-62. doi: 10.1037/10436-002

56. Osterweis M, Solomon F, Green M. CHAPTER 4: reactions to particular types of bereavement. In: Institute of Medicine (US) Committee for the Study of Health Consequences of the Stress of Bereavement, editor. Bereavement: Reactions, Consequences, and Care. Washington, DC: National Academies Press (US) (1984). p. 69-96.

57. Keyes KM, Pratt C, Galea S, McLaughlin KA, Koenen KC, Shear MK. The burden of loss: unexpected death of a loved one and psychiatric disorders across the life course in a national study. Am J Psychiatry. (2014) 171:864-71. doi: 10.1176/appi.ajp.2014.13081132

58. Slavich GM, O’Donovan A, Epel ES, Kemeny ME. Black sheep get the blues: a psychobiological model of social rejection and depression. Neurosci Biobehav Rev. (2010) 35:39-45. doi: 10.1016/j.neubiorev.2010.01.003

59. Buckley T, Sunari D, Marshall A, Bartrop R, McKinley S, Tofler G. Physiological correlates of bereavement and the impact of bereavement interventions. Dialogues Clin Neurosci. (2012) 14:129-39. doi: 10.31887/DCNS.2012.14.2/tbuckley

60. Girgis A, Lambert S, Johnson C, Waller A, Currow D. Physical, psychosocial, relationship, and economic burden of caring for people with cancer: a review. J Oncol Prac. (2013) 9:197-202. doi: 10.1200/JOP.2012.000690

61. Saria MG, Nyamathi A, Phillips LR, Stanton AL, Evangelista L, Kesari $\mathrm{S}$, et al. The hidden morbidity of cancer: burden in caregivers of patients with brain metastases. Nursing Clin North Am. (2017) 52:159-78. doi: 10.1016/j.cnur.2016.10.002

62. Geng HM, Chuang DM, Yang F, Yang Y, Liu WM, Liu LH, et al. Prevalence and determinants of depression in caregivers of cancer patients: a systematic review and meta-analysis. Medicine. (2018) 97:e11863. doi: 10.1097/MD.0000000000011863

63. Maltby KF, Sanderson CR, Lobb EA, Phillips JL. Sleep disturbances in caregivers of patients with advanced cancer: a systematic review. Palliat Support Care. (2017) 15:125-40. doi: 10.1017/S1478951516001024

64. Johansen S, Cvancarova M, Ruland C. The effect of cancer patients' and their family caregivers' physical and emotional symptoms on caregiver burden. Cancer Nursing. (2018) 41:91-9. doi: 10.1097/NCC.0000000000000493

65. Illi J, Miaskowski C, Cooper B, Levine JD, Dunn L, West C, et al. Association between pro- and anti-inflammatory cytokine genes and a symptom cluster of pain, fatigue, sleep disturbance, and depression. Cytokine. (2012) 58:43747. doi: $10.1016 /$ j.cyto.2012.02.015

66. Bonanno GA, Wortman CB, Nesse RM. Prospective patterns of resilience and maladjustment during widowhood. Psychol Aging. (2004) 19:260-71. doi: 10.1037/0882-7974.19.2.260

67. Bonanno GA, Wortman CB, Lehman DR, Tweed RG, Haring M, Sonnega $\mathrm{J}$, et al. Resilience to loss and chronic grief: a prospective study from preloss to 18-months postloss. J Pers Soc Psychol. (2002) 83:1150-64. doi: 10.1037/0022-3514.83.5.1150

68. Lundorff M, Holmgren H, Zachariae R, Farver-Vestergaard I, O’Connor M. Prevalence of prolonged grief disorder in adult bereavement: a systematic review and meta-analysis. J Affect Disord. (2017) 212:138-49. doi: 10.1016/j.jad.2017.01.030

69. Prigerson HG, Horowitz MJ, Jacobs SC, Parkes CM, Aslan M, Goodkin $\mathrm{K}$, et al. Prolonged grief disorder: psychometric validation of criteria proposed for DSM-V and ICD-11. PLoS medicine. (2009) 6:e1000121. doi: 10.1371/journal.pmed.1000121

70. Chen JH, Bierhals AJ, Prigerson HG, Kasl SV, Mazure CM, Jacobs S. Gender differences in the effects of bereavement-related psychological distress in health outcomes. Psychol Med. (1999) 29:367-80. doi: $10.1017 /$ S0033291798008137

71. Shear MK. Clinical practice. complicated grief. N Engl J Med. (2015) 372:15360. doi: 10.1056/NEJMcp1315618

72. Zisook S, Corruble E, Duan N, Iglewicz A, Karam EG, Lanouette N, et al. The bereavement exclusion and DSM-5. Depress Anxiety. (2012) 29:425-43. doi: $10.1002 /$ da. 21927

73. Wakefield JC. The DSM-5 debate over the bereavement exclusion: psychiatric diagnosis and the future of empirically supported treatment. Clin Psychol Rev. (2013) 33:825-45. doi: 10.1016/j.cpr.2013.03.007

74. American Psychiatric Association (APA). Diagnostic and Statistical Manual of Mental Disorders, 5th edition (DSM-5). Washington, DC: American Psychiatric Association (2013). doi: 10.1176/appi.books.9780890 425596

75. Augsburger M, Maercker A. Mental disorders specifically associated with stress in the upcoming ICD-11: An overview. Fortschr Neurol Psychiatr. (2018) 86:156-62. doi: 10.1055/a-0576-6790

76. International Classification of Diseases for Mortality and Morbidity Statistics ERI. World Health Organization (2018).

77. Boelen PA, Smid GE. Disturbed grief: prolonged grief disorder and persistent complex bereavement disorder. BMJ. (2017) 357:j2016. doi: $10.1136 /$ bmj.j2016

78. Tomarken A, Roth A, Holland J, Ganz O, Schachter S, Kose G, et al. Examining the role of trauma, personality, and meaning in young prolonged grievers. Psychooncology. (2012) 21:771-7. doi: 10.1002/pon.1983

79. Kristensen TE, Elklit A, Karstoft K-I. Posttraumatic stress disorder after bereavement: early psychological sequelae of losing a close relative due to terminal cancer. J Loss Trauma. (2012) 17:508-21. doi: 10.1080/15325024.2012.665304

80. Chiu YW, Huang CT, Yin SM, Huang YC, Chien CH, Chuang HY. Determinants of complicated grief in caregivers who cared for terminal cancer patients. Support Care Cancer. (2010) 18:1321-7. doi: 10.1007/s00520-009-0756-6

81. Kim Y, Carver CS, Spiegel D, Mitchell HR, Cannady RS. Role of family caregivers' self-perceived preparedness for the death of the cancer patient in long-term adjustment to bereavement. Psychooncology. (2017) 26:484-92. doi: 10.1002/pon.4042

82. Hall M, Buysse DJ, Dew MA, Prigerson HG, Kupfer DJ, Reynolds CF 3rd. Intrusive thoughts and avoidance behaviors are associated with sleep disturbances in bereavementrelated depression. Depress Anxiety. (1997) 6:106-12. doi: 10.1002/(SICI) 1520-6394.1997.6:3 < 106::AID-DA3>3.0.CO;2-B

83. Lerdal A, Slatten K, Saghaug E, Grov EK, Normann AP, Lee KA, et al. Sleep among bereaved caregivers of patients admitted to hospice: a 1-year longitudinal pilot study. BMJ open. (2016) 6:e009345. doi: 10.1136/bmjopen-2015-009345

84. Chen MA, Lewis MR, Chirinos DA, Murdock KW, Fagundes C. Differential psychological reactions to grief: the role of childhood adversity for depression symptoms among bereaved and non-bereaved adults. Death Stud. (2019) 44:778-86. doi: 10.1080/07481187.2019.1614107

85. Jacobsen J, Vanderwerker L, Block S, Friedlander R, Maciejewski P, Prigerson $\mathrm{H}$. Depression and demoralization as distinct syndromes: preliminary data from a cohort of advanced cancer patients. Indian J Palliat Care. (2006) 12:8-15. doi: 10.4103/0973-1075.25913

86. Prigerson HG, Frank E, Kasl SV, Reynolds CF 3rd, Anderson B, Zubenko GS, et al. Complicated grief and bereavement-related depression as distinct disorders: preliminary empirical validation in elderly bereaved spouses. $\mathrm{Am}$ J Psychiatry. (1995) 152:22-30. doi: 10.1176/ajp.152.1.22

87. Latham AE, Prigerson HG. Suicidality and bereavement: complicated grief as psychiatric disorder presenting greatest risk for suicidality. Suicide Life Threat Behav. (2004) 34:350-62. doi: 10.1521/suli.34.4.350.53737

88. Barry LC, Kasl SV, Prigerson HG. Psychiatric disorders among bereaved persons: the role of perceived circumstances of death and preparedness for death. Am J Geriatr Psychiatry. (2002) 10:447-57. doi: 10.1097/00019442-200207000-00011

89. Melhem NM, Rosales C, Karageorge J, Reynolds CF, 3rd, Frank E, Shear MK. Comorbidity of axis I disorders in patients with traumatic grief. J Clin Psychiatry. (2001) 62:884-7. doi: 10.4088/JCP.v62n1108 
90. Lannen PK, Wolfe J, Prigerson HG, Onelov E, Kreicbergs UC. Unresolved grief in a national sample of bereaved parents: impaired mental and physical health 4 to 9 years later. J Clin Oncol. (2008) 26:5870-6. doi: $10.1200 /$ JCO.2007.14.6738

91. Schulz R, Beach SR, Lind B, Martire LM, Zdaniuk B, Hirsch C, et al. Involvement in caregiving and adjustment to death of a spouse: findings from the caregiver health effects study. JAMA. (2001) 285:3123-9. doi: 10.1001/jama.285.24.3123

92. Stroebe M, Schut H, Stroebe W. Health outcomes of bereavement. Lancet. (2007) 370:1960-73. doi: 10.1016/S0140-6736(07)61816-9

93. Prigerson HG, Bierhals AJ, Kasl SV, Reynolds CF, 3rd, Shear MK, Newsom JT, et al. Complicated grief as a disorder distinct from bereavementrelated depression and anxiety: a replication study. Am J Psychiatry. (1996) 153:1484-6. doi: 10.1176/ajp.153.11.1484

94. Dhar AK, Barton DA. Depression and the link with cardiovascular disease. Front Psychiatry. (2016) 7:33. doi: 10.3389/fpsyt.2016.00033

95. Williams JR Jr. Depression as a mediator between spousal bereavement and mortality from cardiovascular disease: appreciating and managing the adverse health consequences of depression in an elderly surviving spouse. Southern Med J. (2005) 98:90-5. doi: 10.1097/01.SMJ.0000140832. 14297.61

96. Liu R-H, Pan J-Q, Tang X-E, Li B, Liu S-F, Ma W-L. The role of immune abnormality in depression and cardiovascular disease. J Geriatr Cardiol. (2017) 14:703-10. doi: 10.11909/j.issn.1671-5411.2017.11.006

97. Mattina GF, Van Lieshout RJ, Steiner M. Inflammation, depression and cardiovascular disease in women: the role of the immune system across critical reproductive events. Ther Adv Cardiovasc Dis. (2019) 13:1753944719851950. doi: 10.1177/1753944719851950

98. Cohen S, Herbert TB. Health psychology: psychological factors and physical disease from the perspective of human psychoneuroimmunology. Ann Rev Psychol. (1996) 47:113-42. doi: 10.1146/annurev.psych.47.1.113

99. Fagundes CP, Brown RL, Chen MA, Murdock KW, Saucedo L, LeRoy A, et al. Grief, depressive symptoms, and inflammation in the spousally bereaved. Psychoneuroendocrinology. (2019) 100:190-7. doi: 10.1016/j.psyneuen.2018.10.006

100. Kaprio J, Koskenvuo M, Rita H. Mortality after bereavement: a prospective study of 95,647 widowed persons. Am J Public Health. (1987) 77:283-7. doi: 10.2105/AJPH.77.3.283

101. Liu Y-Z, Wang Y-X, Jiang C-L. Inflammation: the common pathway of stress-related diseases. Front Human Neurosci. (2017) 11:316. doi: 10.3389/fnhum.2017.00316

102. Nadrowski P, Chudek J, Skrzypek M, Puzianowska-Kuznicka M, Mossakowska M, Wiecek A, et al. Associations between cardiovascular disease risk factors and IL-6 and hsCRP levels in the elderly. Exp Gerontol. (2016) 85:112-7. doi: 10.1016/j.exger.2016.10.001

103. Shrivastava AK, Singh HV, Raizada A, Singh SK. C-reactive protein, inflammation and coronary heart disease. Egypt Heart J. (2015) 67:89-97. doi: 10.1016/j.ehj.2014.11.005

104. Yeh ET, Anderson HV, Pasceri V, Willerson JT. C-reactive protein: linking inflammation to cardiovascular complications. Circulation. (2001) 104:9745. doi: 10.1161/01.CIR.104.9.974

105. Moon JR, Kondo N, Glymour MM, Subramanian SV. Widowhood and mortality: a meta-analysis. PLOS ONE. (2011) 6:e23465. doi: 10.1371/journal.pone.0023465

106. Young M, Benjamin B, Wallis C. The mortality of widowers. Lancet. (1963) 2:454-6. doi: 10.1016/S0140-6736(63)92193-7

107. Tsuchihashi K, Ueshima K, Uchida T, Oh-mura N, Kimura K, Owa M, et al. Transient left ventricular apical ballooning without coronary artery stenosis: a novel heart syndrome mimicking acute myocardial infarction. Angina pectoris-myocardial infarction investigations in Japan. J Am Coll Cardiol. (2001) 38:11-8. doi: 10.1016/S0735-1097(01)01316-X

108. Templin C, Ghadri JR, Diekmann J, Napp LC, Bataiosu DR, Jaguszewski M, et al. Clinical features and outcomes of takotsubo (stress) cardiomyopathy. N Engl J Med. (2015) 373:929-38. doi: 10.1056/NEJMoa1406761

109. Buckley T, Mihailidou AS, Bartrop R, McKinley S, Ward C, Morel-Kopp $\mathrm{MC}$, et al. Haemodynamic changes during early bereavement: potential contribution to increased cardiovascular risk. Heart Lung Circ. (2011) 20:918. doi: 10.1016/j.hlc.2010.10.073

110. Mausbach BT, Aschbacher K, Patterson TL, von Kanel R, Dimsdale JE, Mills PJ, et al. Effects of placement and bereavement on psychological well-being and cardiovascular risk in Alzheimer's caregivers: a longitudinal analysis. $J$ Psychosom Res. (2007) 62:439-45. doi: 10.1016/j.jpsychores.2006.10.011

111. Kaptoge S, Di Angelantonio E, Lowe G, Pepys MB, Thompson SG, Collins $\mathrm{R}$, et al. C-reactive protein concentration and risk of coronary heart disease, stroke, and mortality: an individual participant meta-analysis. Lancet. (2010) 375:132-40. doi: 10.1016/S0140-6736(09)61717-7

112. Willeit P, Thompson A, Aspelund T, Rumley A, Eiriksdottir G, Lowe G, et al. Hemostatic factors and risk of coronary heart disease in general populations: new prospective study and updated meta-analyses. PLoS ONE. (2013) 8:e55175. doi: 10.1371/journal.pone.0055175

113. Lagraauw HM, Kuiper J, Bot I. Acute and chronic psychological stress as risk factors for cardiovascular disease: insights gained from epidemiological, clinical and experimental studies. Brain Behav Immun. (2015) 50:18-30. doi: 10.1016/j.bbi.2015.08.007

114. Antoni MH, Lutgendorf SK, Cole SW, Dhabhar FS, Sephton SE, McDonald PG, et al. The influence of bio-behavioural factors on tumour biology: pathways and mechanisms. Nat Rev Cancer. (2006) 6:240-8. doi: $10.1038 / \mathrm{nrc1} 1820$

115. Armaiz-Pena GN, Cole SW, Lutgendorf SK, Sood AK. Neuroendocrine influences on cancer progression. Brain Behav Immun. (2013) 30:S19-25. doi: 10.1016/j.bbi.2012.06.005

116. Cole SW, Sood AK. Molecular pathways: beta-adrenergic signaling in cancer. Clin Cancer Res. (2012) 18:1201-6. doi: 10.1158/1078-0432.CCR-11-0641

117. Levav I, Kohn R, Iscovich J, Abramson JH, Tsai WY, Vigdorovich D. Cancer incidence and survival following bereavement. Am J Public Health. (2000) 90:1601-7. doi: 10.2105/AJPH.90.10.1601

118. Cole SW, Nagaraja AS, Lutgendorf SK, Green PA, Sood AK. Sympathetic nervous system regulation of the tumour microenvironment. Nat Rev Cancer. (2015) 15:563-72. doi: 10.1038/nrc3978

119. Lutgendorf SK, Andersen BL. Biobehavioral approaches to cancer progression and survival: mechanisms and interventions. Am Psychol. (2015) 70:186-97. doi: 10.1037/a0035730

120. Costanzo ES, Sood AK, Lutgendorf SK. Biobehavioral influences on cancer progression. Immunol Allergy Clin North Am. (2011) 31:109-32. doi: 10.1016/j.iac.2010.09.001

121. Lamkin DM, Sloan EK, Patel AJ, Chiang BS, Pimentel MA, Ma JC, et al. Chronic stress enhances progression of acute lymphoblastic leukemia via beta-adrenergic signaling. Brain Behav Immun. (2012) 26:635-41. doi: 10.1016/j.bbi.2012.01.013

122. Lutgendorf SK, Sood AK. Biobehavioral factors and cancer progression: physiological pathways and mechanisms. Psychosom Med. (2011) 73:724-30. doi: 10.1097/PSY.0b013e318235be76

123. Hackett RA, Steptoe A. Type 2 diabetes mellitus and psychological stress: a modifiable risk factor. Nat Rev Endocrinol. (2017) 13:547-60. doi: 10.1038/nrendo.2017.64

124. Tsuneki H, Tokai E, Sugawara C, Wada T, Sakurai T, Sasaoka T. Hypothalamic orexin prevents hepatic insulin resistance induced by social defeat stress in mice. Neuropeptides. (2013) 47:213-9. doi: 10.1016/j.npep.2013.02.002

125. Olsen J, Li J, Precht DH. Hospitalization because of diabetes and bereavement: a national cohort study of parents who lost a child. Diabet Med. (2005) 22:1338-42. doi: 10.1111/j.1464-5491.2005.01642.x

126. Virk J, Li J, Vestergaard M, Obel C, Kristensen JK, Olsen J. Prenatal exposure to bereavement and type-2 diabetes: a Danish longitudinal population based study. PLoS ONE. (2012) 7:e43508-e. doi: 10.1371/journal.pone.0043508

127. Slavich GM. Psychoneuroimmunology of stress and mental health. In Harkness KL, Hayden EP, editors. The Oxford Handbook of Stress and Mental Health. New York, NY: Oxford University Press (2020). p. 519-46.

128. Phillips AC, Carroll D, Burns VE, Ring C, Macleod J, Drayson M. Bereavement and marriage are associated with antibody response to influenza vaccination in the elderly. Brain Behavior Immun. (2006) 20:27989. doi: 10.1016/j.bbi.2005.08.003

129. Ong AD, Fuller-Rowell TE, Bonanno GA, Almeida DM. Spousal loss predicts alterations in diurnal cortisol activity through prospective changes in positive emotion. Health Psychol. (2011) 30:220-7. doi: 10.1037/a0022262

130. Irwin M, Daniels M, Risch SC, Bloom E, Weiner H. Plasma cortisol and natural killer cell activity during bereavement. Biol Psychiatry. (1988) 24:1738. doi: 10.1016/0006-3223(88)90272-7

131. Richardson VE, Bennett KM, Carr D, Gallagher S, Kim J, Fields N. How does bereavement get under the skin? The effects of late-life spousal 
loss on cortisol levels. J Gerontol B Psychol Sci Soc Sci. (2015) 70:341-7. doi: 10.1093/geronb/gbt116

132. O'Connor MF, Wellisch DK, Stanton AL, Olmstead R, Irwin MR. Diurnal cortisol in complicated and non-complicated grief: slope differences across the day. Psychoneuroendocrinology. (2012) 37:725-8. doi: 10.1016/j.psyneuen.2011.08.009

133. Chirinos DA, Ong JC, Garcini LM, Alvarado D, Fagundes C. Bereavement, self-reported sleep disturbances, and inflammation: results from project heart. Psychosom Med. (2019) 81:67-73. doi: 10.1097/PSY.0000000000000645

134. Kim TH, Carroll JE, An SK, Seeman TE, Namkoong K, Lee E. Associations between actigraphy-assessed sleep, inflammatory markers, and insulin resistance in the Midlife Development in the United States (MIDUS) study. Sleep Med. (2016) 27-28:72-9. doi: 10.1016/j.sleep.2016. 07.023

135. Felger JC. Role of inflammation in depression and treatment implications. Handb Exp Pharmacol. (2019) 250:255-86. doi: 10.1007/164_2018_166

136. Biondi M, Picardi A. Clinical and biological aspects of bereavement and lossinduced depression: a reappraisal. Psychother Psychosom. (1996) 65:229-45. doi: $10.1159 / 000289082$

137. Sompayrac L. How the Immune System Works. 5th Edition. Singapore: Wiley Blackwell (2016)

138. Schleifer SJ, Keller SE, Camerino M, Thornton JC, Stein M. Suppression of lymphocyte stimulation following bereavement. JAMA. (1983) 250:374-7. doi: 10.1001/jama.1983.03340030034024

139. O'Connor M-F, Schultze-Florey CR, Irwin MR, Arevalo JMG, Cole SW. Divergent gene expression responses to complicated grief and non-complicated grief. Brain Behav Immun. (2014) 37:78-83. doi: 10.1016/j.bbi.2013.12.017

140. Baumeister D, Akhtar R, Ciufolini S, Pariante CM, Mondelli V. Childhood trauma and adulthood inflammation: a meta-analysis of peripheral Creactive protein, interleukin- 6 and tumour necrosis factor- $\alpha$. Mol Psychiatry. (2015) 21:642. doi: 10.1038/mp.2015.67

141. Lam JCW, Shields GS, Trainor BC, Slavich GM, Yonelinas AP. Greater lifetime stress exposure predicts blunted cortisol but heightened DHEA responses to acute stress. Stress Health. (2019) 35:15-26. doi: $10.1002 /$ smi.2835

142. Slavich GM. Understanding inflammation, its regulation, and relevance for health: a top scientific and public priority. Brain Behav Immun. (2015) 45:13-4. doi: 10.1016/j.bbi.2014.10.012

143. Slavich GM, Monroe SM, Gotlib IH. Early parental loss and depression history: associations with recent life stress in major depressive disorder. $J$ Psychiatr Res. (2011) 45:1146-52. doi: 10.1016/j.jpsychires.2011.03.004

144. Cole SW. Elevating the perspective on human stress genomics. Psychoneuroendocrinology. (2010) 35:955-62. doi: 10.1016/j.psyneuen.2010.06.008

145. O'Mahony SM, Marchesi JR, Scully P, Codling C, Ceolho AM, Quigley EM, et al. Early life stress alters behavior, immunity, and microbiota in rats: implications for irritable bowel syndrome and psychiatric illnesses. Biol Psychiatry. (2009) 65:263-7. doi: 10.1016/j.biopsych.2008.06.026

146. Molina-Torres G, Rodriguez-Arrastia M, Roman P, Sanchez-Labraca N, Cardona D. Stress and the gut microbiota-brain axis. Behav Pharmacol. (2019) 30:187-200. doi: 10.1097/FBP.0000000000000478

147. Bennett EJ, Tennant CC, Piesse C, Badcock CA, Kellow JE. Level of chronic life stress predicts clinical outcome in irritable bowel syndrome. Gut. (1998) 43:256-61. doi: 10.1136/gut.43.2.256

148. Moloney RD, Johnson AC, O'Mahony SM, Dinan TG, Greenwood-Van Meerveld B, Cryan JF. Stress and the microbiota-gut-brain axis in visceral pain: relevance to irritable bowel syndrome. CNS Neurosci Ther. (2016) 22:102-17. doi: $10.1111 / \mathrm{cns} .12490$

149. Iebba V, Nicoletti M, Schippa S. Gut microbiota and the immune system: an intimate partnership in health and disease. Int J Immunopathol Pharmacol. (2012) 25:823-33. doi: 10.1177/039463201202500401

150. Opazo MC, Ortega-Rocha EM, Coronado-Arrázola I, Bonifaz LC, Boudin $\mathrm{H}$, Neunlist $\mathrm{M}$, et al. Intestinal microbiota influences nonintestinal related autoimmune diseases. Front Microbiol. (2018) 9:432. doi: 10.3389/fmicb.2018.00432

151. Jiang H, Ling Z, Zhang Y, Mao H, Ma Z, Yin Y, et al. Altered fecal microbiota composition in patients with major depressive disorder. Brain Behav Immun. (2015) 48:186-94. doi: 10.1016/j.bbi.2015.03.016
152. Rao AV, Bested AC, Beaulne TM, Katzman MA, Iorio C, Berardi JM, et al. A randomized, double-blind, placebo-controlled pilot study of a probiotic in emotional symptoms of chronic fatigue syndrome. Gut Pathog. (2009) 1:6. doi: 10.1186/1757-4749-1-6

153. Steenbergen L, Sellaro R, van Hemert S, Bosch JA, Colzato LS. A randomized controlled trial to test the effect of multispecies probiotics on cognitive reactivity to sad mood. Brain Behav Immun. (2015) 48:258-64. doi: 10.1016/j.bbi.2015.04.003

154. Valles-Colomer M, Falony G, Darzi Y, Tigchelaar EF, Wang J, Tito RY, et al. The neuroactive potential of the human gut microbiota in quality of life and depression. Nat Microbiol. (2019) 4:623-32. doi: 10.1038/s41564-018-0337-x

155. Humbel F, Rieder JH, Franc Y, Juillerat P, Scharl M, Misselwitz B, et al. Association of alterations in intestinal microbiota with impaired psychological function in patients with inflammatory bowel diseases in remission. Clin Gastroenterol Hepatol. (2019) 18:2019-2029.e11. doi: 10.1016/j.cgh.2019.09.022

156. Aroniadis OC, Drossman DA, Simren M. A perspective on brain-gut communication: the american gastroenterology association and american psychosomatic society joint symposium on brain-gut interactions and the intestinal microenvironment. Psychosom Med. (2017) 79:847-56. doi: 10.1097/PSY.0000000000000431

157. Fukudo S. Autonomic dysregulation in IBS. Nat Rev Gastroenterol Hepatol. (2013) 10:569. doi: 10.1038/nrgastro.2013.166

158. Xu D, Gao J, Gillilland M, 3rd, Wu X, Song I, Kao JY, et al. Rifaximin alters intestinal bacteria and prevents stress-induced gut inflammation and visceral hyperalgesia in rats. Gastroenterology. (2014) 146:484-96.e4. doi: 10.1053/j.gastro.2013.10.026

159. Epel ES, Blackburn EH, Lin J, Dhabhar FS, Adler NE, Morrow JD, et al. Accelerated telomere shortening in response to life stress. Proc Natl Acad Sci USA. (2004) 101:17312-5. doi: 10.1073/pnas.0407162101

160. Rizvi S, Raza ST, Mahdi F. Telomere length variations in aging and age-related diseases. Curr Aging Sci. (2014) 7:161-7. doi: $10.2174 / 1874609808666150122153151$

161. Shammas MA. Telomeres, lifestyle, cancer, and aging. Curr Opin Clin Nutr Metab Care. (2011) 14:28-34. doi: 10.1097/MCO.0b013e32834121b1

162. Mathur MB, Epel E, Kind S, Desai M, Parks CG, Sandler DP, et al. Perceived stress and telomere length: A systematic review, meta-analysis, and methodologic considerations for advancing the field. Brain Behav Immun. (2016) 54:158-69. doi: 10.1016/j.bbi.2016.02.002

163. Gouin JP, Hantsoo L, Kiecolt-Glaser JK. Immune dysregulation and chronic stress among older adults: a review. Neuroimmunomodulation. (2008) 15:251-9. doi: 10.1159/000156468

164. Shalev I, Entringer S, Wadhwa PD, Wolkowitz OM, Puterman E, Lin J, et al. Stress and telomere biology: a lifespan perspective. Psychoneuroendocrinology. (2013) 38:1835-42. doi: 10.1016/j.psyneuen. 2013.03.010

165. Entringer S, Epel ES, Kumsta R, Lin J, Hellhammer DH, Blackburn EH, et al. Stress exposure in intrauterine life is associated with shorter telomere length in young adulthood. Proc Natl Acad Sci USA. (2011) 108:E513-8. doi: $10.1073 /$ pnas. 1107759108

166. Lazarides C, Epel ES, Lin J, Blackburn EH, Voelkle MC, Buss C, et al. Maternal pro-inflammatory state during pregnancy and newborn leukocyte telomere length: A prospective investigation. Brain Behav Immun. (2019) 80:419-26. doi: 10.1016/j.bbi.2019.04.021

167. Send TS, Gilles M, Codd V, Wolf I, Bardtke S, Streit F, et al. Telomere length in newborns is related to maternal stress during pregnancy. Neuropsychopharmacology. (2017) 42:2407-13. doi: 10.1038/npp.2017.73

168. Fuentes E, Fuentes M, Alarcón M, Palomo I. Immune system dysfunction in the elderly. Anais Academia Brasileira de Ciencias. (2017) 89:285-99. doi: 10.1590/0001-3765201720160487

169. Nikolich-Žugich J. The twilight of immunity: emerging concepts in aging of the immune system. Nat Immunol. (2018) 19:10-9. doi: 10.1038/s41590-017-0006-x

170. Wu D, Meydani SN. Age-associated changes in immune and inflammatory responses: impact of vitamin E intervention. J Leukocyte Biol. (2008) 84:90014. doi: $10.1189 / \mathrm{jlb} .0108023$

171. Burleson MH, Poehlmann KM, Hawkley LC, Ernst JM, Berntson GG, Malarkey WB, et al. Stress-related immune changes in middle-aged and older women: 1-year consistency of individual differences. Health Psychol. (2002) 21:321-31. doi: 10.1037/0278-6133.21.4.321 
172. Hansson RO, Stroebe MS. Grief, older adulthood. In: Gullota TP, Bloom M, editors. Encyclopedia of Primary Prevention and Health Promotion. Boston, MA: Springer (2003).p. 515-21. doi: 10.1007/978-1-4615-0195-4_75

173. Vitlic A, Khanfer R, Lord JM, Carroll D, Phillips AC. Bereavement reduces neutrophil oxidative burst only in older adults: role of the HPA axis and immunesenescence. Immun Ageing. (2014) 11:13. doi: 10.1186/1742-4933-11-13

174. Khanfer R, Lord JM, Phillips AC. Neutrophil function and cortisol:DHEAS ratio in bereaved older adults. Brain Behav Immun. (2011) 25:1182-6. doi: 10.1016/j.bbi.2011.03.008

175. Phillips AC, Burns VE, Lord JM. Stress and exercise: getting the balance right for aging immunity. Exerc Sport Sci Rev. (2007) 35:35-9. doi: 10.1097/jes.0b013e31802d7008

176. Vitlic A, Lord JM, Carroll D, Phillips AC. Increased risk of infection in bereaved older adults: from broken heart to broken immune system. Adv Neuroimmun Biol. (2015) 6:25-30. doi: 10.3233/NIB-150106

177. Bennett JM, Fagundes CP, Kiecolt-Glaser JK. The chronic stress of caregiving accelerates the natural aging of the immune system. In: Bosch JA, Phillips AC, Lord JM, editors. Immunosenescence: Psychosocial and Behavioral Determinants. New York, NY: Springer (2013). p. 35-46. doi: 10.1007/978-1-4614-4776-4_3

178. Cohen S, Janicki-Deverts D, Miller GE. Psychological stress and disease. JAMA. (2007) 298:1685-7. doi: 10.1001/jama.298.14.1685

179. Kiecolt-Glaser JK, Gouin JP, Weng NP, Malarkey WB, Beversdorf DQ, Glaser R. Childhood adversity heightens the impact of later-life caregiving stress on telomere length and inflammation. Psychosom Med. (2011) 73:16-22. doi: 10.1097/PSY.0b013e31820573b6

180. Fagundes CP, Glaser R, Kiecolt-Glaser JK. Stressful early life experiences and immune dysregulation across the lifespan. Brain Behav Immun. (2013) 27:8-12. doi: 10.1016/j.bbi.2012.06.014

181. Bonanno GA, Westphal M, Mancini AD. Resilience to loss and potential trauma. Ann Rev Clin Psychol. (2011) 7:511-35. doi: 10.1146/annurev-clinpsy-032210-104526

182. Rutter M. Resilience concepts and findings: implications for family therapy. J Family Ther. (1999) 21:119-44. doi: 10.1111/1467-6427.00108

183. Galatzer-Levy IR, Bonanno GA. Beyond normality in the study of bereavement: heterogeneity in depression outcomes following loss in older adults. Soc Sci Med. (2012) 74:1987-94. doi: 10.1016/j.socscimed.2012.02.022

184. Maccallum F, Galatzer-Levy IR, Bonanno GA. Trajectories of depression following spousal and child bereavement: a comparison of the heterogeneity in outcomes. J Psychiatr Res. (2015) 69:72-9. doi: 10.1016/j.jpsychires.2015.07.017

185. Bonanno GA. Loss, trauma, and human resilience: have we underestimated the human capacity to thrive after extremely aversive events? Am Psychol. (2004) 59:20-8. doi: 10.1037/0003-066X.59.1.20

186. Bottomley JS, Burke LA, Neimeyer RA. Domains of social support that predict bereavement distress following homicide loss: assessing need and satisfaction. OMEGA. (2015) 75:3-25. doi: 10.1177/0030222815612282

187. Stroebe W, Zech E, Stroebe MS, Abakoumkin G. Does social support help in bereavement? J Soc Clin Psychol. (2005) 24:1030-50. doi: 10.1521 /jscp.2005.24.7.1030

188. Bonanno GA, Moskowitz JT, Papa A, Folkman S. Resilience to loss in bereaved spouses, bereaved parents, and bereaved gay men. J Pers Soc Psychol. (2005) 88:827-43. doi: 10.1037/0022-3514.88.5.827

189. Field NP, Gao B, Paderna L. Continuing bonds in bereavement: an attachment theory based perspective. Death Stud. (2005) 29:277-99. doi: 10.1080/07481180590923689

190. Moskowitz JT, Folkman S, Acree M. Do positive psychological states shed light on recovery from bereavement? Findings from a 3-year longitudinal study. Death Stud. (2003) 27:471-500. doi: 10.1080/07481180302885

191. Boelen PA. Optimism in prolonged grief and depression following loss: a three-wave longitudinal study. Psychiatry Res. (2015) 227:313-7. doi: 10.1016/j.psychres.2015.03.009

192. Bonanno GA, Burton CL. Regulatory flexibility: an individual differences perspective on coping and emotion regulation. Perspect Psychol Sci. (2013) 8:591-612. doi: 10.1177/1745691613504116
193. Walsh K, King M, Jones L, Tookman A, Blizard R. Spiritual beliefs may affect outcome of bereavement: prospective study. BMJ. (2002) 324:1551. doi: 10.1136/bmj.324.7353.1551

194. Killikelly C, Bauer S, Maercker A. The assessment of grief in refugees and post-conflict survivors: a narrative review of etic and emic research. Front Psychol. (2018) 9:1957. doi: 10.3389/fpsyg.2018.01957

195. Robinaugh DJ, LeBlanc NJ, Vuletich HA, McNally RJ. Network analysis of persistent complex bereavement disorder in conjugally bereaved adults. J Abnorm psychol. (2014) 123:510-22. doi: 10.1037/abn00 00002

196. Huh HJ, Kim KH, Lee H-K, Chae J-H. Attachment styles, grief responses, and the moderating role of coping strategies in parents bereaved by the sewol ferry accident. Eur J Psychotraumatol. (2018) 8(Suppl. 6):1424446. doi: 10.1080/20008198.2018.1424446

197. Mancini AD, Sinan B, Bonanno GA. Predictors of prolonged grief, resilience, and recovery among bereaved spouses. J Clin Psychol. (2015) 71:1245-58. doi: $10.1002 /$ jclp. 22224

198. Stroebe M, Schut $H$. The dual process model of coping with bereavement: a decade on. OMEGA. (2010) 61:273-89. doi: 10.2190/OM.61.4.b

199. Schut MSH. THE dual process model of coping with bereavement: rationale and description. Death Stud. (1999) 23:197-224. doi: 10.1080/074811899201046

200. Rohleder N, Marin TJ, Ma R, Miller GE. Biologic cost of caring for a cancer patient: dysregulation of pro- and anti-inflammatory signaling pathways. $J$ Clin Oncol. (2009) 27:2909-15. doi: 10.1200/JCO.2008.18.7435

201. Kent EE, Rowland JH, Northouse L, Litzelman K, Chou W-YS, Shelburne $\mathrm{N}$, et al. Caring for caregivers and patients: research and clinical priorities for informal cancer caregiving. Cancer. (2016) 122:1987-95. doi: $10.1002 /$ cncr.29939

202. Schüssler-Fiorenza Rose SM, Contrepois K, Moneghetti KJ, Zhou W, Mishra T, Mataraso S, et al. A longitudinal big data approach for precision health. Nat Med. (2019) 25:792-804. doi: 10.1038/s41591-0190414-6

203. Slavich GM. Social safety theory: a biologically based evolutionary perspective on life stress, health, and behavior. Ann Rev Clin Psychol. (2020) 16:265-95. doi: 10.1146/annurev-clinpsy-032816-045159

204. Slavich GM, Shields GS. Assessing lifetime stress exposure using the stress and adversity inventory for adults (adult strain): an overview and initial validation. Psychosom Med. (2018) 80:17-27. doi: 10.1097/PSY.0000000000000534

205. Stahl ST, Schulz R. Changes in routine health behaviors following latelife bereavement: a systematic review. J Behav Med. (2014) 37:736-55. doi: 10.1007/s10865-013-9524-7

206. Stahl ST, Emanuel J, Albert SM, Dew MA, Schulz R, Robbins-Welty G, et al. Design and rationale for a technology-based healthy lifestyle intervention in older adults grieving the loss of a spouse. Contemp Clin Trials Commun. (2017) 8:99-105. doi: 10.1016/j.conctc.2017.09.002

207. Usami S, Jacobucci R, Hayes T. The performance of latent growth curve model-based structural equation model trees to uncover population heterogeneity in growth trajectories. Comput Stat. (2019) 34:1-22. doi: 10.1007/s00180-018-0815-x

Conflict of Interest: The authors declare that the research was conducted in the absence of any commercial or financial relationships that could be construed as a potential conflict of interest.

The reviewer LR declared a past co-authorship with one of the author GS to the handling editor.

Copyright (c) 2020 Seiler, von Känel and Slavich. This is an open-access article distributed under the terms of the Creative Commons Attribution License (CC BY). The use, distribution or reproduction in other forums is permitted, provided the original author(s) and the copyright owner(s) are credited and that the original publication in this journal is cited, in accordance with accepted academic practice. No use, distribution or reproduction is permitted which does not comply with these terms. 